\title{
Influence of shielding gas nozzle design on power density distribution in low current TIG welding arcs
}

\author{
Stephan Egerland ${ }^{123}$ Paul Colegrove ${ }^{4}$ and Stewart Williams ${ }^{2}$
}

\begin{abstract}
This study investigated the impact of the shielding gas nozzle design, especially diameter variation, to understand its influence on the anodic power density distribution, while maintaining either the volumetric gas flow rate or the gas flow velocity constant. In addition, the effects of surface oxidation and the flow type (laminar or turbulent) and how it is affected by the nozzle diameter was studied. Arcs of 50 amperes (A) were highly unstable while increasing the welding current to $100 \mathrm{~A}$ led to an arc stabilisation with the investigated nozzle types. Similar to previous investigations Gaussian distribution profiles were not found with density maxima shifted away from the arc axis.
\end{abstract}

Keywords: Split-anode calorimetry, TIG arc welding, arc energy, arc power

${ }^{1}$ Corresponding author: s.a.egerland@.cranfield.ac.uk

${ }^{2}$ Cranfield University, College Road, Cranfield MK43 0AL, UK

${ }^{3}$ Fronius International GmbH, Günter-Fronius-Straße 1, 4600 Wels Austria

${ }^{4}$ Formerly with Cranfield University, College Road, Cranfield MK43 0AL, UK 


\section{Introduction}

Despite being used for producing high quality weld joints, Tungsten Inert Gas (TIG) welding can show arc instabilities when applied with low electrical current [1-4], Figure 1.

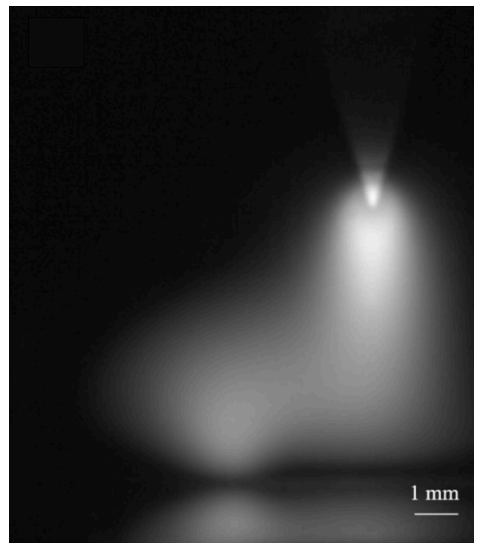

Figure 1 TIG welding arc sustained upon water cooled copper anode and deviated from the arc axis while applying $50 \mathrm{~A}$ welding current and $6 \mathrm{~mm}$ electrode tip to workpiece distance. Note that the deviation depicted is independent from arc interaction with the anode split plane interface.

Increasing the welding current overcomes these phenomena [1,2], however, this is not always feasible as low arc energy is required for some joints. Different hypotheses are discussed on the primary reasons causing arc deviation and instability; e.g. doping variation over the tungsten cathode cross section induced by evaporation of doping elements [3], or low welding current paired with ambient pressure variations [4]. However, we presume that these assumptions were consistently made on the fundamental assumption that the radial arc energy density profile is a Gaussian distribution, hence, the energy density maximum can be found close to, or at the arc centre. This approach is proposed by a predominant number of researchers who have applied different methodologies to prove this physical behaviour. Besides using spectroscopy [5-12] and numerical simulation [13-22], the arc pressure was measured and correlated with the radial arc energy density [23-26]. A relatively safe and technically proven method to quantify the energy distribution in TIG welding arcs is referred to as 'split anode calorimetry' and involves applying two water cooled, non-melting copper anodes separated by a split plane of low width $(0.075$ $\mathrm{mm})$. Figure 2 schematically depicts the calorimeter principle explained in greater depth elsewhere [27, $28]$.

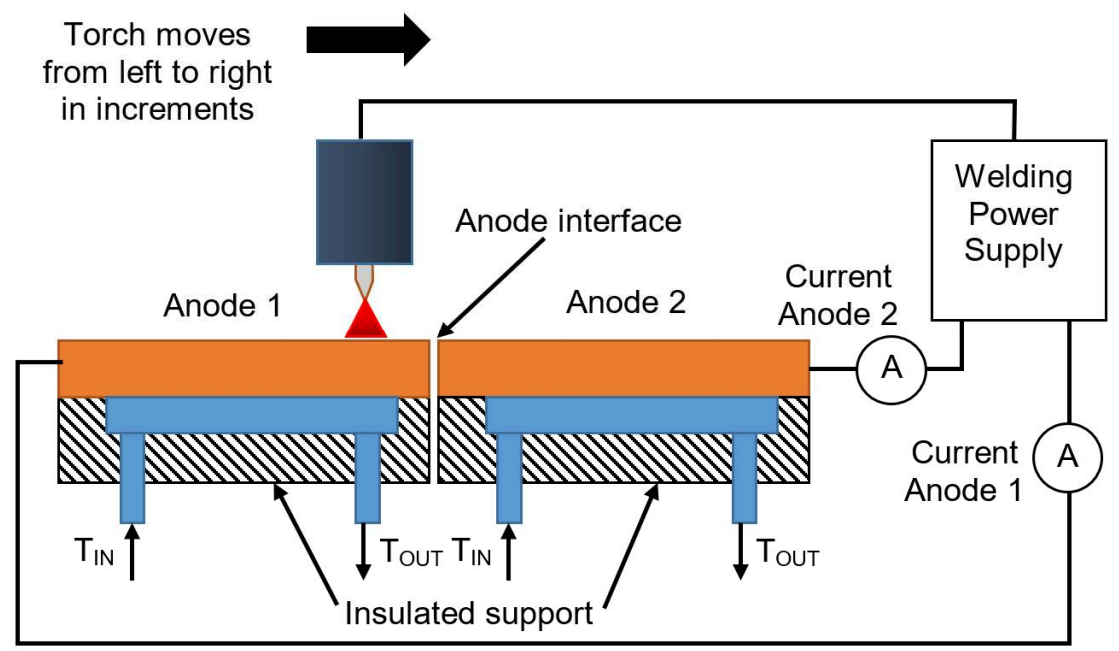

Figure 2 Schematic split anode calorimeter principle [27].

Split anode calorimetry allows the calculation of the electrical current density as well as the electrical and calorimetric arc power transferred to the copper anodes. This can be achieved by calculating the 
product of the specific heat capacity of the coolant used (water in this study), its volumetric flow rate and the difference in temperature, measured between water in- and outlet. Developed by Nestor [29] and Nestor and Olsen [30] a number of researchers have used this method to evaluate the radial energy distribution of TIG- [10, 11, 14, 29, 31-35] and Plasma Welding arcs [36].

In a previous study by the authors [28] a large diameter shielding gas nozzle was used, designed to produce laminar gas shielding to produce an arc unaffected by turbulent flow likely to cause arc fluctuations and hence, negatively influence the radial energy density distribution. Nonetheless arc instabilities were found which, to a certain degree, have led to unpredictable results in the arc current density distribution. Different suggestions have been discussed in [28] on the root causes for the phenomena observed, however, as consistent arc stability was achieved through the measurement, in particular while the arc was crossing the split plane interface area, it was found that Gaussian energy density distribution is not apparent in the arc. If this happens in a real welding application, where the TIG cathode is centred at the split gap between the two sheets, the off axis maxima in the radial energy may cause the arc instabilities observed during welding under these conditions.

Although gas nozzle effects are particularly known from Plasma Arc Welding (PAW) where applying a nozzle is used to constrict the arc and to improve its axial stability [37], there is little research literature on the impact of nozzle design in TIG welding. Considerably more investigations were conducted in MIG/MAG welding; for example Ramsey et al. [38] have numerically modelled and experimentally validated the effects caused by different shielding gas nozzle diameters to mitigate side draughts as occur in practical on-site MIG/MAG welding applications. Although their investigation was for $\mathrm{Ar} / \mathrm{CO}_{2}$ blends $\left(80 \mathrm{Ar} / 20 \mathrm{CO}_{2}\right)$ and the shielding gas nozzle design is considerably different to TIG-nozzles, they could find substantial differences in the nozzle exit velocities which increased as the nozzle diameter decreased. Unlike other studies, Ramsey et al. have involved the arc plasma by simulating a constant temperature field which could lead to proper correlation between the numerical model and the experiment.

Campbell et al. [39] in a numerical and experimental investigation also dealing with MIG/MAG welding, and mainly based upon the work of Ramsey [38], have varied the gas flow conditions by changing the shielding gas nozzle geometry; i.e. they have used a "double helix insert", a "restricted plate", and an "internal plate" in the shielding gas nozzle to study the effects caused by these hardware inserts. Campbell et al. showed that the reduction of the shielding gas nozzle diameter and the inclusion of a circumferential internal plate as an additional constriction, could increase the nozzle exit velocity which, in turn, allowed a reduced gas volumetric flow rate, without degrading welding quality.

Dreher et al. [40] reported on the numerical simulation of MIG/MAG shielding gas nozzle effects both with and without the arc plasma which is stated to be of crucial importance. The numerical models showed significant turbulences to occur within and in front of the MIG/MAG shielding gas nozzle. The authors also refer to the so-called 'Schlieren' Technique, which makes use of density variations as present e.g. in the shielding gas surrounding the arc. This method was also used by Siewert et al. [41] who were analysing shielding gas flow conditions in MIG/MAG-, TIG-, and Plasma Arc Welding. Volumetric flow rate threshold values are provided in [41] for the TIG process; stating that "shielding gas flow rates of $30 \mathrm{~L} / \mathrm{min}$ and more" cause "turbulences surrounding the arc", however, unfortunately insufficient detail on the TIG experimental set up prevent comparison with the present study. For PAW the authors found indications that, despite turbulent flow due to high flow rates, this had no detrimental effect on weld bead protection. 


\section{Aim and objectives}

The aim was to understand the factors that affect the stability of low current TIG arcs especially when used with a split anode calorimeter. This was achieved with the following objectives:

a. To understand the effects of shielding gas nozzle diameter variation; the energy distribution in the arc was studied, to determine whether this had an impact on arc stability.

b. To use efficient visualisation techniques capable of clarifying the shielding gas flow behaviour and its effects on arc stability under different experimental conditions.

c. To perform experiments in a shielding gas chamber, that provided a protective inert gas atmosphere to determine whether surface oxidation is the primary cause for the arc instabilities observed in previous studies $[27,28]$.

\section{Methodology}

Figure 3 is a semi-transparent, schematic diagram depicting the calorimeter body used in this investigation consisting of a temperature resistant fibre reinforced plastic material. The two oxygen-free copper anodes applied were accurately machined to dimensions of $80 \mathrm{~mm} \times 62 \mathrm{~mm} \times 12 \mathrm{~mm}$. Prior to arc application the anodes were prepared by longitudinal (parallel to arc traverse direction) wet grinding (500-grit abrasive paper) and commercial scouring pads (Scotch-Brite ${ }^{\circledR}$ ). Before each arc sequence a commercial polish (SC Johnson 'Stahlfix') was used to polish the surface subsequently cleaned by using isopropyl alcohol. The distance between the anodes was maintained constant by using DuPont ${ }^{\mathbb{B}}$ KAPTON ${ }^{\circledR} \mathrm{HN}$ '3mil' heat and electrical resistant polyimide film of $75 \mu \mathrm{m}$ thickness.

a)

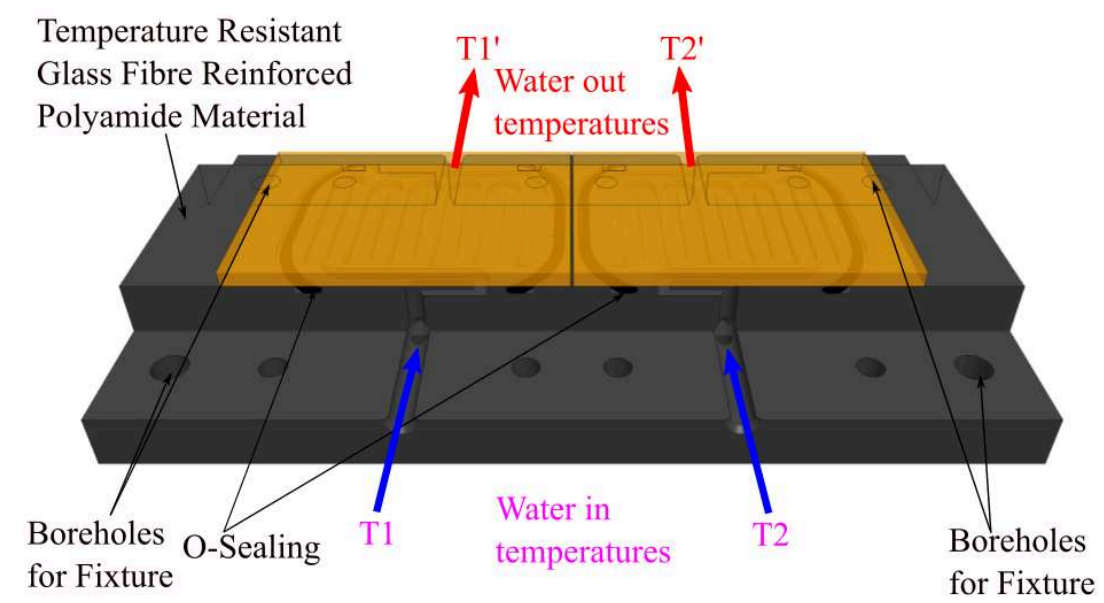

b)

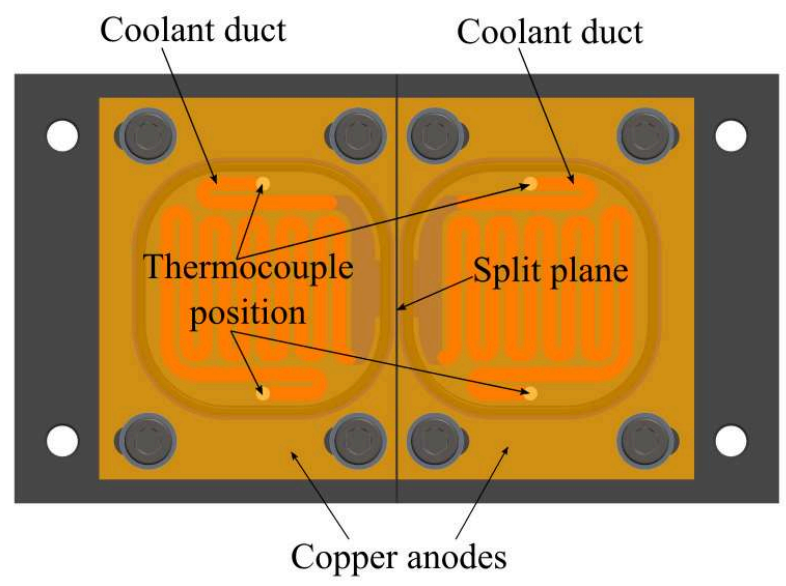

Figure $3 a$ Schematic representation of calorimeter body including copper anodes in semi-transparent side-view; $b$ calorimeter body in top view. 
Besides the split anode calorimeter, the experimental set-up consisted of a 'FRONIUS Magic Wave 2200' TIG welding power source including a 'FK 2200' cooling unit. The water cooled TIG torch 'TTW 3000 a $\mathrm{F} / \mathrm{F}++/ \mathrm{UD} / 4 \mathrm{~m}$ ' was mounted to a commercial high precision linear manipulator Type 'IAI RCA 2 SA3C' and additionally movable by a mechanical gantry system.

After positioning the welding torch the arc was ignited on 'anode 1' and a delay time of 10 seconds was applied to allow arc stabilisation and to achieve a balance between water inlet and outlet temperatures. A Type 'Agilent 37490a' 20 channel multiplexer data acquisition system, used to collect the raw data, was then appropriately triggered to take 5 measurements with a delay time of 1 second between each measurement. The manipulator was programmed to traverse the arc in $0.2 \mathrm{~mm}$ increments across the anodes and an additional delay time of 0.5 seconds was added after each measurement cycle was finished and the torch was moved to the next measurement starting position. To collect additional visible information on arc appearance phenomena through each incremental measurement a commercial Type 'IDS UI-1226LE' CMOS camera was used to capture two images per increment; i.e. at increment initiation and termination.

$2 \%$ cerium oxide doped tungsten electrodes of $2.4 \mathrm{~mm}$ diameter were used, longitudinally ground prior to each measurement sequence to obtain a $36^{\circ}$ included angle. The shielding gas used was argon of purity $99.996 \%$. The fundamental experimental data are shown in Table 1 .

Table 1 Essential experimental data.

\begin{tabular}{lcc}
\hline \multicolumn{1}{c}{ Parameter } & Unit & Value \\
\hline Current $(\mathrm{I})$ & $\mathrm{A}$ & $50 / 100$ \\
ETWD $^{5}$ & $\mathrm{~mm}$ & $3.0 / 6.0$ \\
Vertex angle $(\alpha)$ & $\circ$ & 36 \\
Cathode composition & - & $\mathrm{WCeO}_{2}$ \\
Cathode diameter & $\mathrm{mm}$ & 2.4 \\
\hline
\end{tabular}

This investigation was targeted at reducing the shielding gas nozzle diameter versus an earlier study which has applied a $30 \mathrm{~mm}$ diameter nozzle [28]. To compare the different nozzle diameters either the volumetric gas flow rate (Set 1) or shielding gas flow velocity (Set 2) derived from [28] was maintained constant as shown in Table 2. This was done to determine how each affected the power distribution in the arc.

Table 2 Experimental values depending on shielding gas nozzle diameter.

\begin{tabular}{|c|c|c|c|c|c|}
\hline & \multirow[t]{2}{*}{ Quantity } & \multicolumn{4}{|c|}{ Nozzle diameter / mm } \\
\hline & & 5 & 10 & 15 & 20 \\
\hline \multirow{2}{*}{ Set 1} & $\dot{V}\left(\mathrm{Ls}^{-1}\right)$ & 0.3 & 0.3 & 0.3 & 0.3 \\
\hline & $v\left(\mathrm{~ms}^{-1}\right)$ & 15.3 & 3.8 & 1.7 & 0.92 \\
\hline \multirow{2}{*}{ Set 2} & $\dot{V}\left(\mathrm{Ls}^{-1}\right)$ & 0.0083 & 0.030 & 0.075 & 0.13 \\
\hline & $v\left(\mathrm{~ms}^{-1}\right)$ & 0.42 & 0.42 & 0.42 & 0.42 \\
\hline
\end{tabular}

\footnotetext{
${ }^{5}$ Electrode tip to workpiece distance.
} 
Figure 4 shows the shielding gas nozzle types produced and used for the experiments.

a)

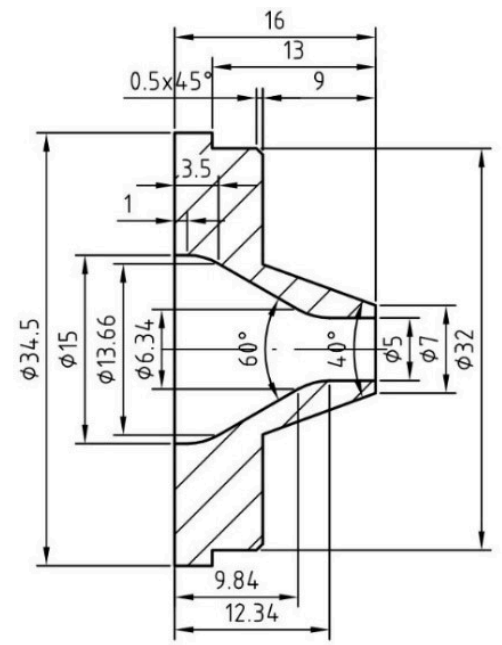

c)

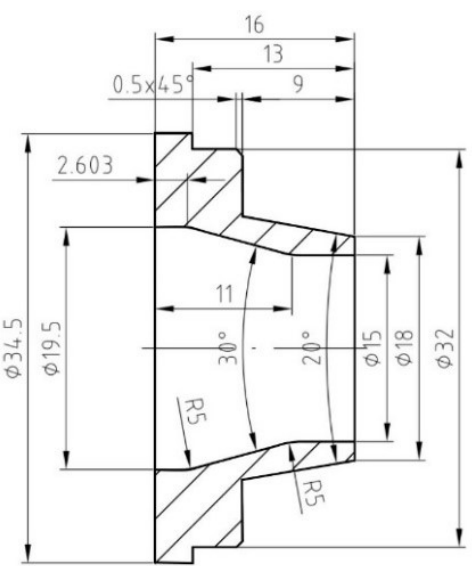

b)

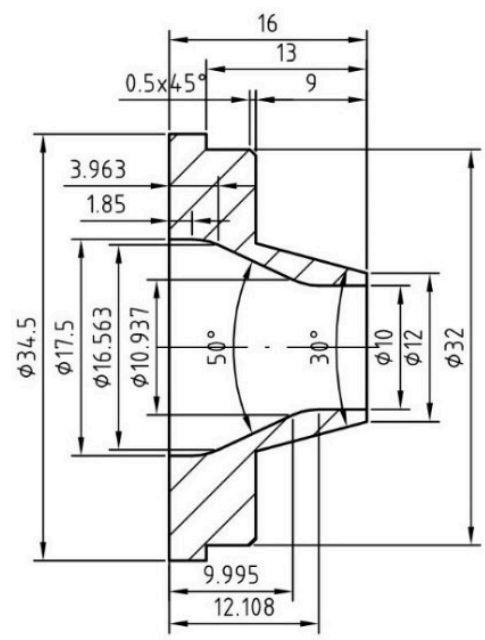

d)

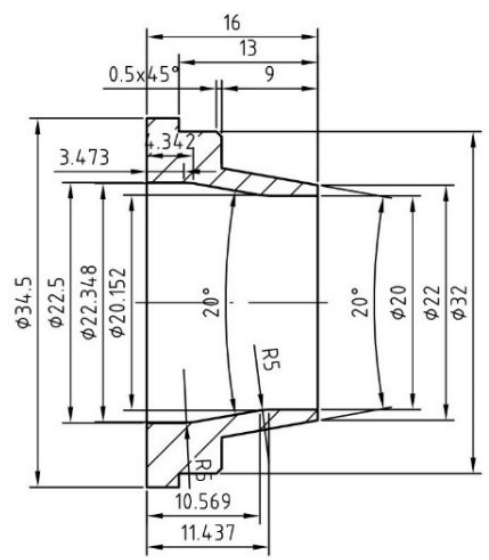

Figure $4 a$ Prototype shielding gas nozzle diameter $5 \mathrm{~mm}$; $b$ diameter $10 \mathrm{~mm} ; c$ diameter $15 \mathrm{~mm}$, and $d$ diameter $20 \mathrm{~mm}$. Note: dimensions in $\mathrm{mm}$.

Figure 5 shows the commercial (FRONIUS TTWA F/F++/UD/4m) TIG welding torch equipped with the $20 \mathrm{~mm}$ diameter prototype shielding gas nozzle and also reveals the mesh gas diffuser used to generate laminar gas flow conditions.

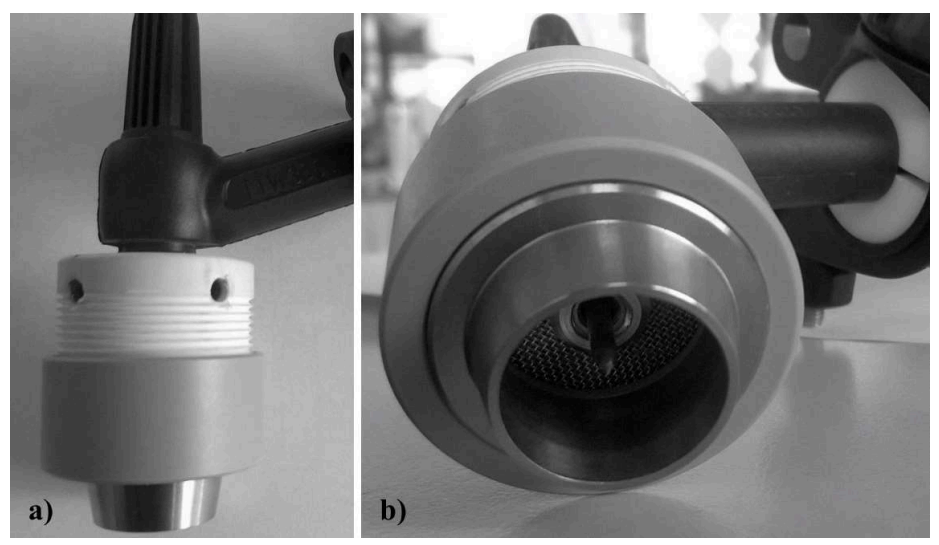

Figure $5 a$ Side-view of TIG welding torch equipped with ø $20 \mathrm{~mm}$ shielding gas nozzle; $b 20 \mathrm{~mm}$ diameter nozzle mounted to torch and showing cathode and mesh gas diffuser.

While the arc is traversed across the anodes the welding current, the welding voltage, as well as the water temperature and flow rate were measured. As the anode split plane is approached; 'anode 1' electrical current and the water temperature drop as a function of the arc position while the values 
increase when crossing to 'anode 2'. This leads to the characteristic profile schematically depicted in Figure 6.

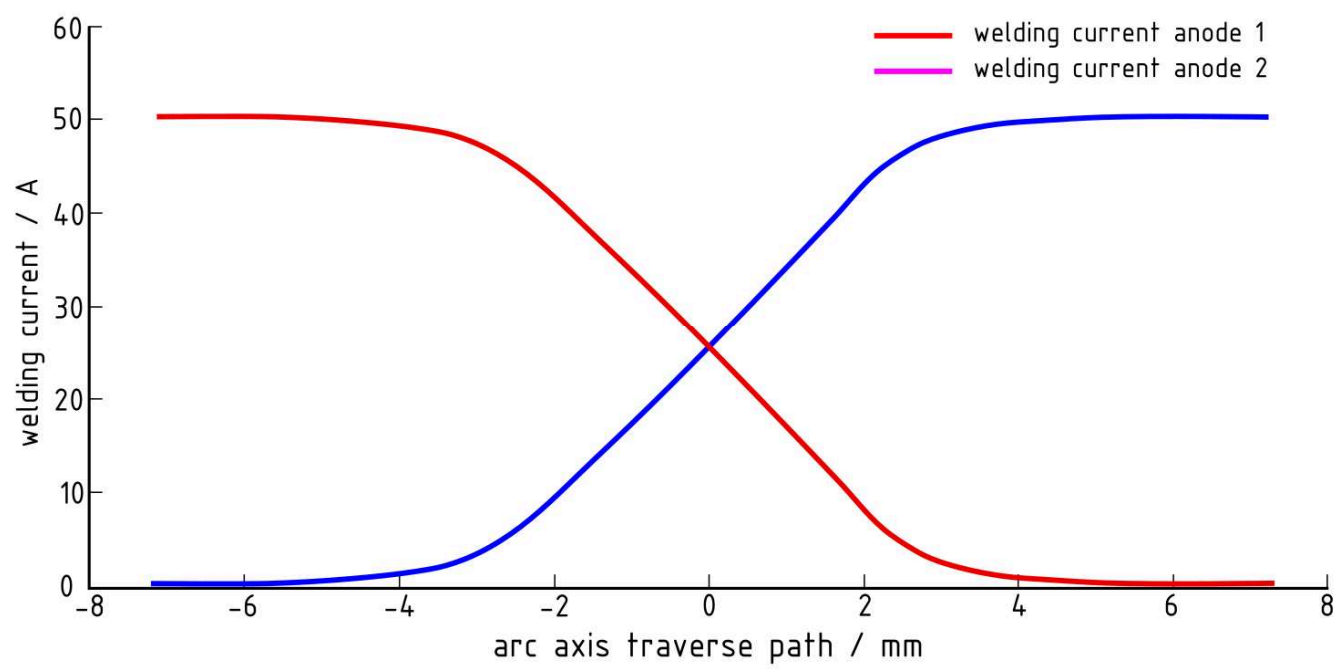

Figure 6 Current distribution profile while the arc traverses from 'anode 1' to 'anode 2'. Note: ' $x$-axis zero' represents the anode split interface centre

\subsection{Calorimetric power density}

The heat input- or calorimetric power density was computed by averaging the 5 raw data values of the quantities previously described during each incremental measurement sequence and applying the following equation:

$$
Q=\dot{V} \rho c_{p} \Delta T
$$

With $Q$ representing the heat transferred to the anodes and absorbed by the calorimeter coolant (water), $\Delta T$ as the difference between inlet and outlet temperature at the particular point in time, and $\dot{V}$ as the volumetric coolant flow rate. Using data from [42] the density $\rho$ of the calorimeter coolant was calculated as $996.5 \mathrm{kgm}^{-3}$, while a specific heat $\left(c_{p}\right)$ of $4182 \mathrm{Jkg}^{-1} \mathrm{~K}^{-1}$ was applied according to the data by [43]. MATLAB ${ }^{\circledR}$ was used to apply the inverse Abel Transformation, developed by Nestor [29] and Nestor and Olsen [30] and described elsewhere [27, 28] to obtain the current- or power density distribution as a function of the arc radius.

\subsection{Shielding gas flow visualisation}

It is important to understand whether volumetric gas flow rate variation would provide consistent laminar flow conditions. Gas flow visualisation trials in cold condition; i.e. without arc application, were conducted to assess the general applicability of the nozzle design; however, a simplified method compared to the 'Schlieren' technique was used which, although found beneficial by other researchers $[40,41]$ in welding gas flow investigations, requires an extensive experimental set up [41]. We could achieve efficient shielding gas flow visualisation by applying a commercially available atomiser, Type 'JOYETEC CUBIS ${ }^{\circledR}$ '. Using this device, a liquid 50\% propylene glycol and $50 \%$ glycerine solution was vaporised and subsequently added to the regular shielding gas flow. The welding torch, equipped with the different prototype nozzles, was clamped into a gantry manipulator which allowed spatial adjustment of all parts relatively to one another. The visualisation of the vapour was achieved by using two focusable red laser line modules, Type 'LFL650-5-12(9x20)90-F250', of $650 \mathrm{~nm}$ wavelength. Either a base plate was used in appropriate distance to the cathode tip to simulate the anode surface, or the tests were carried out devoid of the base plate to understand the shielding gas free flow behaviour; i.e. to represent the flow without workpiece surface interaction. Figure 7 reveals part of the experimental set up deployed for the gas flow condition visualisation trial series as depicted in Table 2. 
IIW Doc. XII-2409-19

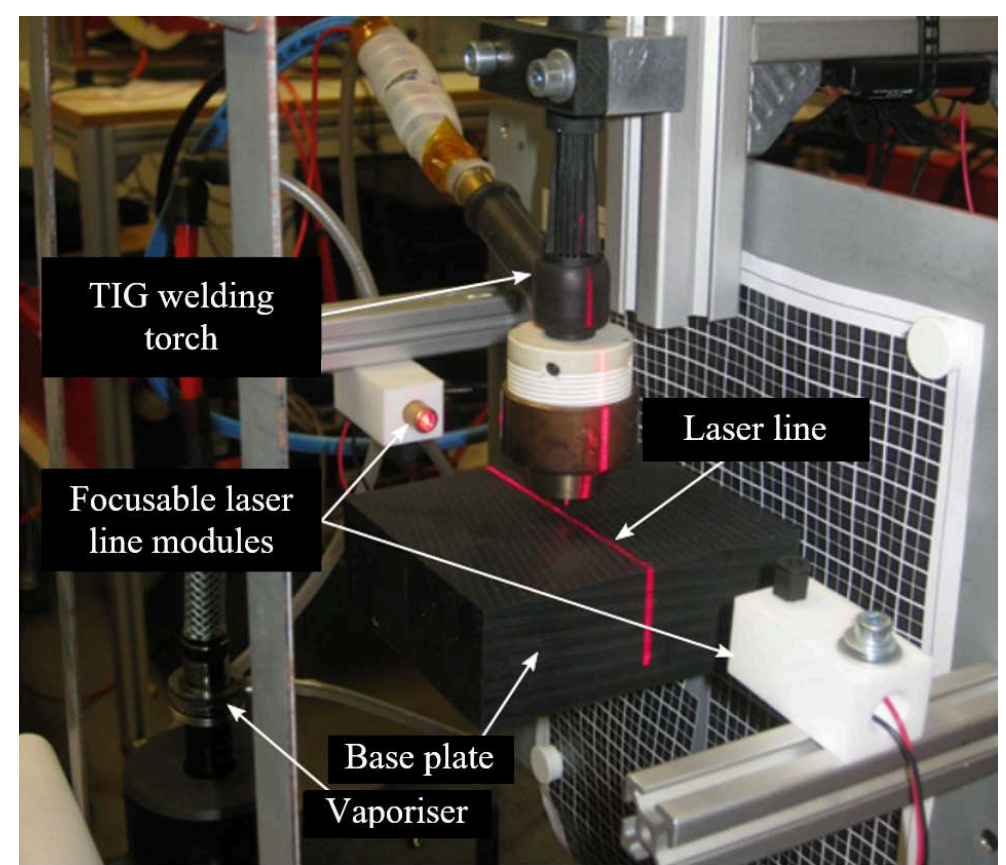

Figure 7 Shielding gas flow visualisation experimental set up.

Stimulated by Norrish [44] it was attempted to reveal whether the gas mesh diffuser used in the experimental set up was in general even capable of improving the gas flow to achieve laminar shielding gas flow. Figure 8 (a) visualises turbulences in deploying the $\varnothing 30 \mathrm{~mm}$ reference nozzle devoid of using the gas mesh diffuser, while Figure 8 (b) shows the application of the diffuser and how it causes the gas flow to become homogeneously laminar. The mesh diffuser has a significant positive impact and enables the generation of laminar flow conditions.

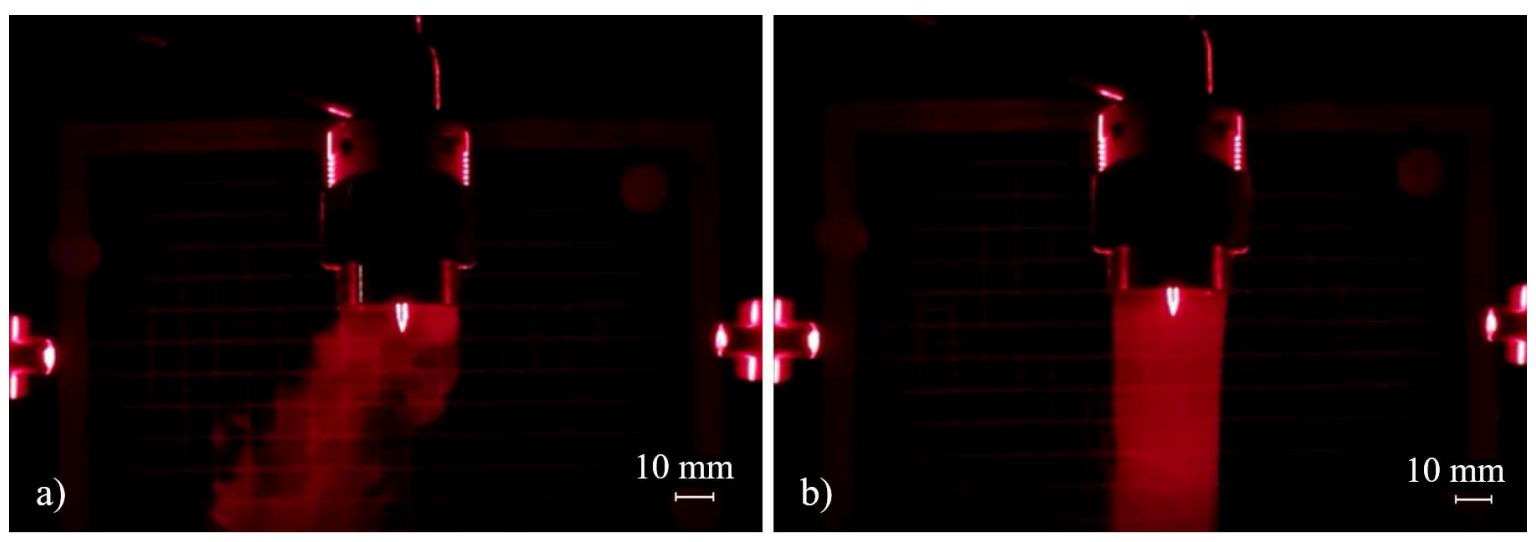

Figure $8 a$ Turbulent gas flow deploying the $\varnothing 30 \mathrm{~mm}$ shielding gas nozzle without mesh diffuser; $b$ mesh diffuser installed and causing laminar flow conditions. Note: gas flow rate $=0.3 \mathrm{Ls}^{-1}$. 


\subsection{Shielding gas chamber tests}

In addition to the aforementioned experimental set up it was decided to conduct a random sample investigation, using a chamber, shown in Figure 9, to completely protect the anodes. The primary target in deploying this chamber was to understand whether tests could be achieved without surface oxidation, and to understand whether this affected the quantitative output.

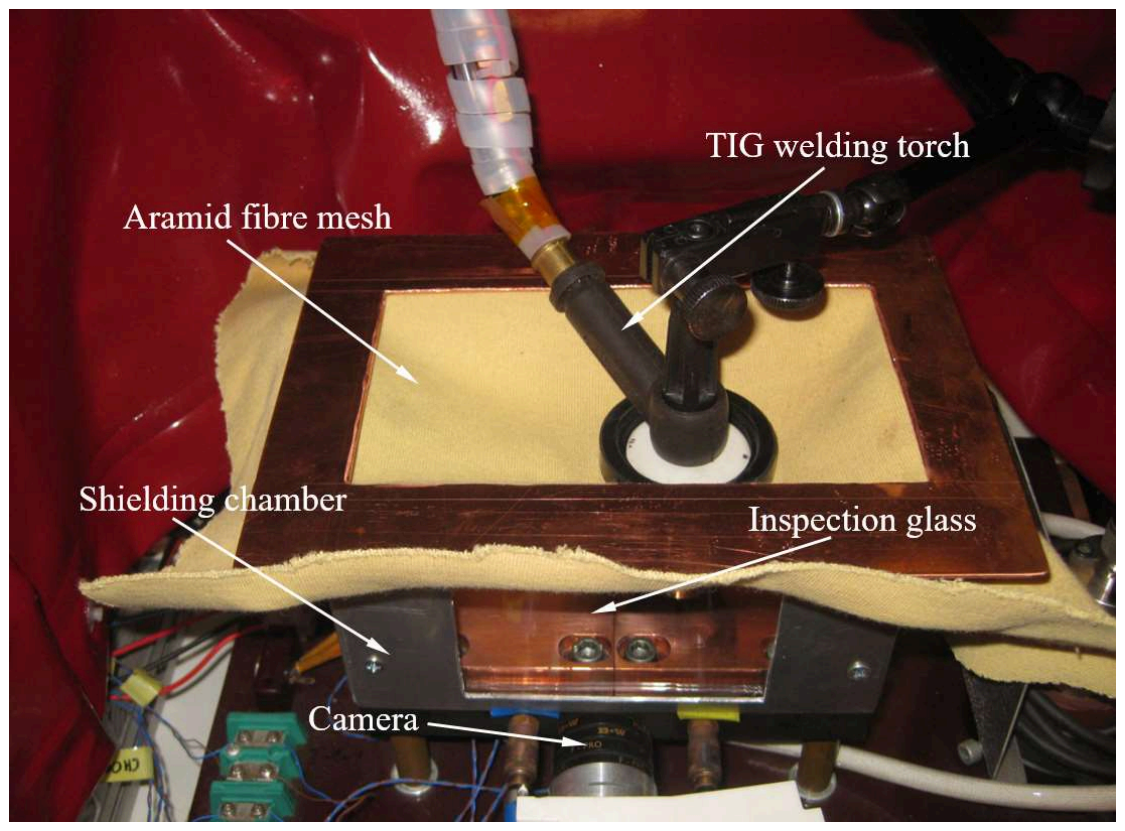

Figure 9 Shielding gas chamber for random sample test conduction.

The small aluminium chamber (including inspection glass) was produced precisely to fit to the calorimeter polyimide block. Covered by a temperature resistant aramid fibre mesh (KEVLAR ${ }^{\circledR} 29$ ) of $1.44 \mathrm{gcm}^{-3}$ density and $550{ }^{\circ} \mathrm{C}$ decomposition temperature [45], it allowed movement of the torch without mechanical resistance caused by the fibre mesh, but nonetheless, due to the mesh's permeability to the shielding gas, reliably to achieve ambient shielding gas pressure conditions inside the chamber. The random check was performed using the $30 \mathrm{~mm}$ diameter nozzle as also applied in [28] and $50 \mathrm{~A}$ welding current along with 3.0 and $6.0 \mathrm{~mm}$ ETWD. The oxygen content within the chamber was accurately checked before arc ignition, using a PBI-Dansensor 'OXI-3' Type Portable Oxygen Indicator which assured that a maximum relative $\mathrm{O}_{2}$ value of $0.3 \%$ was obtained during the test.

\section{Results}

The following sections describe the results calculated from the measurement raw data according to the experimental data in Table 1 and Table 2. They primarily deal with the calorimetric power- or heat flux density distribution and compare with the reference results dealt with in the previous study by the authors [28] to demonstrate the effects caused by the shielding gas nozzle diameter variation. Unlike the previous study, the first and second derivative of the radial energy distribution were not smoothed in this investigation.

\subsection{Nozzle diameter $15 \mathrm{~mm}$}

Figure 10 (a-d) compares the mean values of 'anode 1' computed from three arc application sequences and both welding current applications and deploying the $15 \mathrm{~mm}$ diameter nozzle. Figure 10 (a) plots the 50 A results for $3.0 \mathrm{~mm}$ ETWD and reveals for the constant flow velocity and very low flow rates, an extreme density maximum (notice the y-axis scale), and a distinct density maximum for the constant flow rate, away from the arc axis. Interestingly neither of these maxima can be found in the $\varnothing 30 \mathrm{~mm}$ reference nozzle results (blue line) which show a relatively flat heat input profile across the arc radius. Figure 10 (a) also shows a collapse of the density around the split plane area when deploying constant flow velocity. The comparison for $50 \mathrm{~A}$, however, applying $6.0 \mathrm{~mm}$ ETWD, is depicted in Figure 10 
(b). Density maxima can be found at $\sim 1.5 \mathrm{~mm}$ away from the arc centre along with severe density collapses close to the split plane area both with constant flow rate and flow velocity. The 100 A results for $3.0 \mathrm{~mm}$ ETWD indicate flatter curves for both conditions being distributed similar to the reference nozzle curve, Figure 10 (c). This is comparable to [27, 28] where in general a more Gaussian density profile was found with no distinct extrema in the electric current density. Figure 10 (d) for 100 amperes and $6.0 \mathrm{~mm}$ arc gap notably indicates the output differences compared with applying $50 \mathrm{~A}$ (Figure 10 b) and shows how doubling the welding current, even with higher ETWD, can stabilise the conditions. Apart from the measurement collapsing phenomena while applying 50 A welding current - which will be dealt with in the 'Discussion' section - we could observe a significant heat input density fluctuation with increasing ETWD and low volumetric shielding gas flow rate, Figure 10 (b).
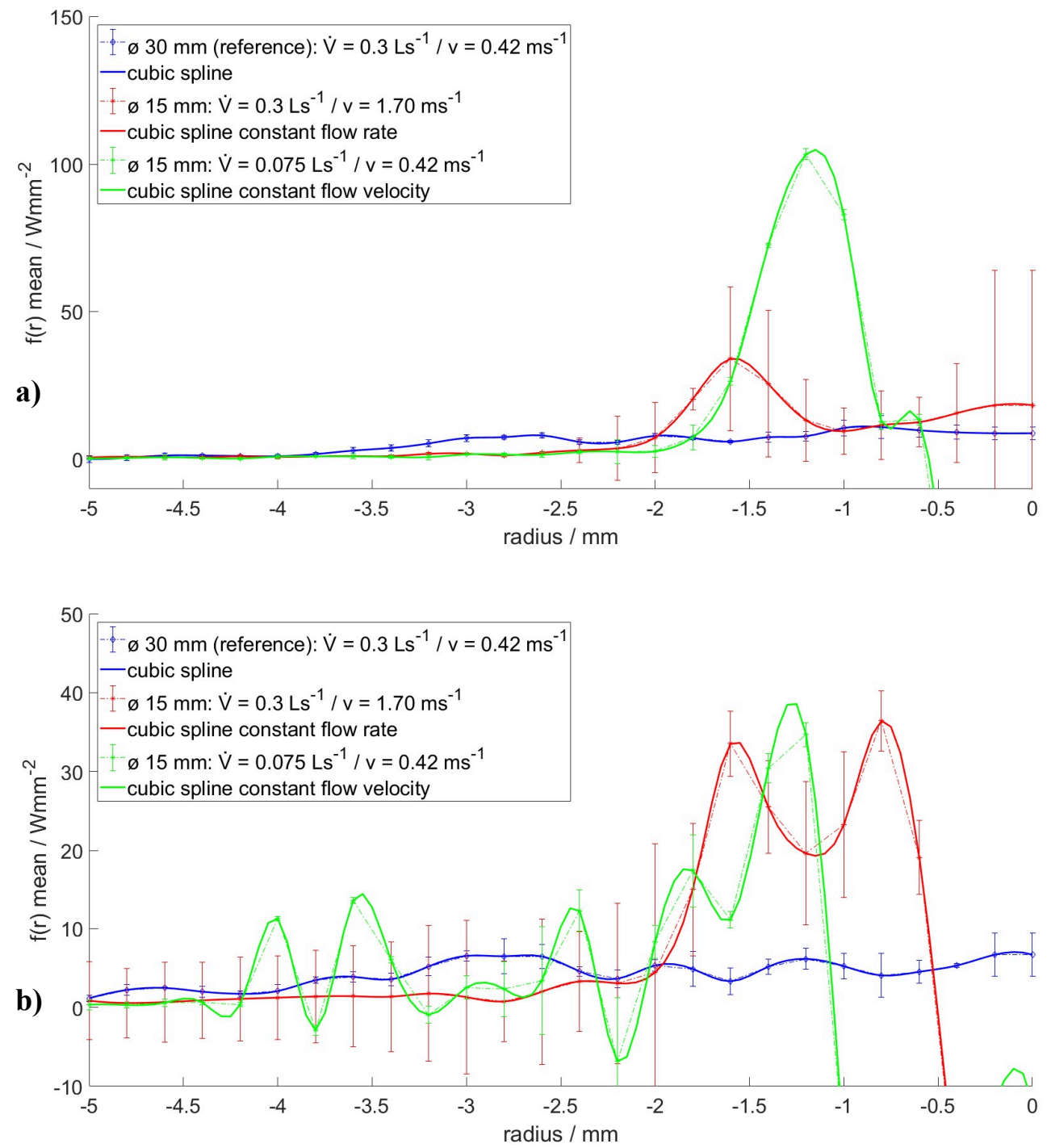

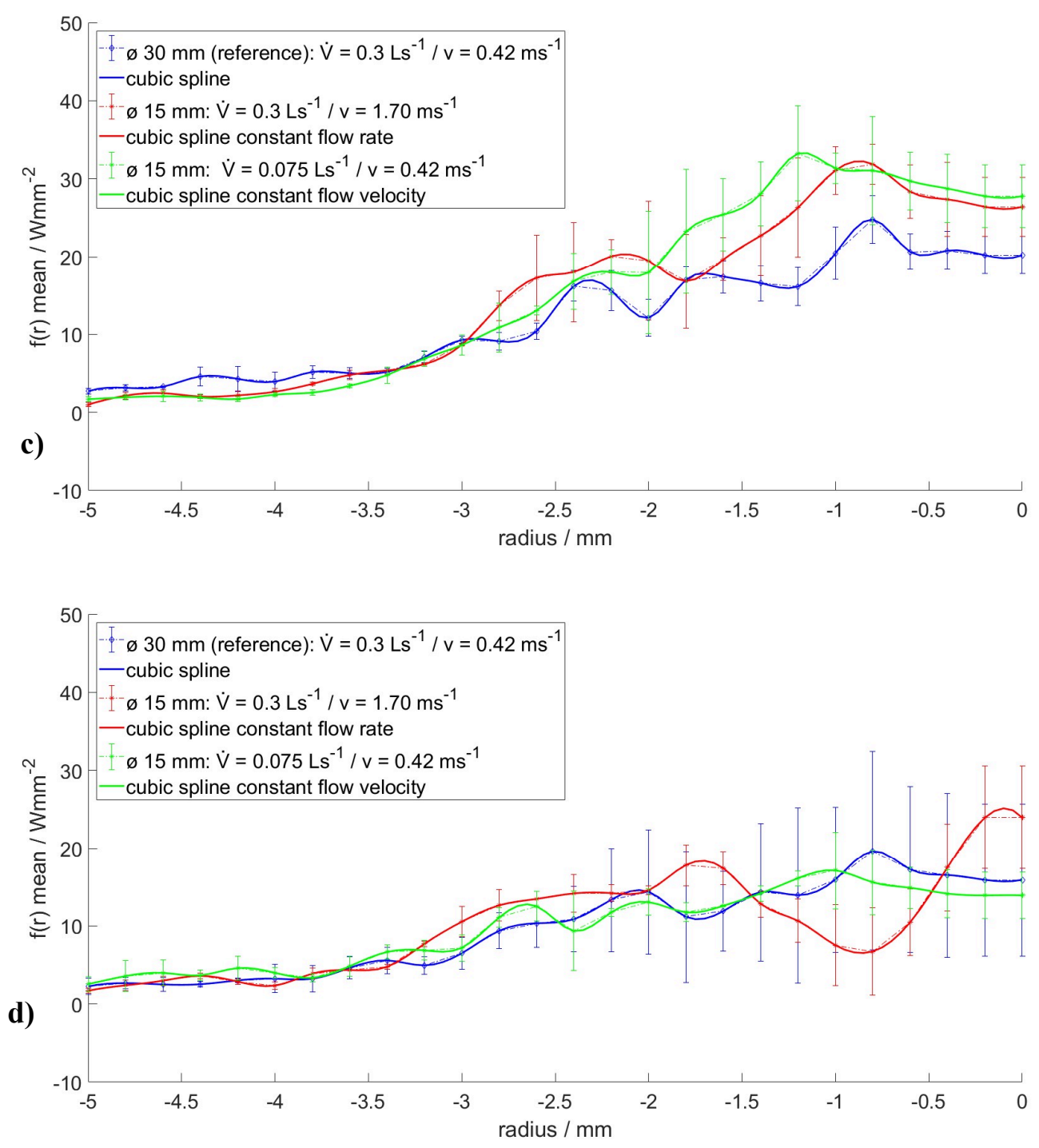

Figure 10 Calorimetric power density comparison of $50 \mathrm{~A}$ and $100 \mathrm{~A}$ welding current, using $15 \mathrm{~mm}$ diameter nozzle and maintaining either volumetric flow rate or flow velocity constant. Error bars represent standard deviation. $a-50 \mathrm{~A} / \mathrm{ETWD}=3.0 \mathrm{~mm} ; b-50 \mathrm{~A} / \mathrm{ETWD}=6.0 \mathrm{~mm} ; c-100 \mathrm{~A} /$ $\mathrm{ETWD}=3.0 \mathrm{~mm} ; d-100 \mathrm{~A} / \mathrm{ETWD}=6.0 \mathrm{~mm}$.

\subsection{Nozzle diameter $20 \mathrm{~mm}$}

For the $20 \mathrm{~mm}$ diameter nozzle, Figure 11 (a) for the $3.0 \mathrm{~mm}$ ETWD at 50 A welding current, reveals a collapsing behaviour with constant shielding gas flow rate which, however, is not the case with constant flow velocity. On the contrary, a relatively stable (note the small noise in the results) density peak can be found at a radial distance of $\sim 2 \mathrm{~mm}$ away from the arc centre, which is comparable to the current density measurements in [28]. This peak can also be identified in Figure 11 (b), depicting the results for $6.0 \mathrm{~mm}$ ETWD, however, in a lower intensity vs. the smaller arc gap. It is to be emphasised that a density maximum cannot be found whereas deploying the reference nozzle type (blue line in Figure $11 \mathrm{a} / \mathrm{b}$ ). Figure 11 (c) and (d) reveal the findings for the $100 \mathrm{~A}$ arc application and show a much higher stability compared with the $50 \mathrm{~A}$ welding current results. Collapsing around the split plane area is entirely missing and the heat input density distribution appears alike the ø $15 \mathrm{~mm}$ nozzle type with increasing values towards the arc centre; thereby showing also similarity versus the results found in [28] for the current density distribution. 
IIW Doc. XII-2409-19
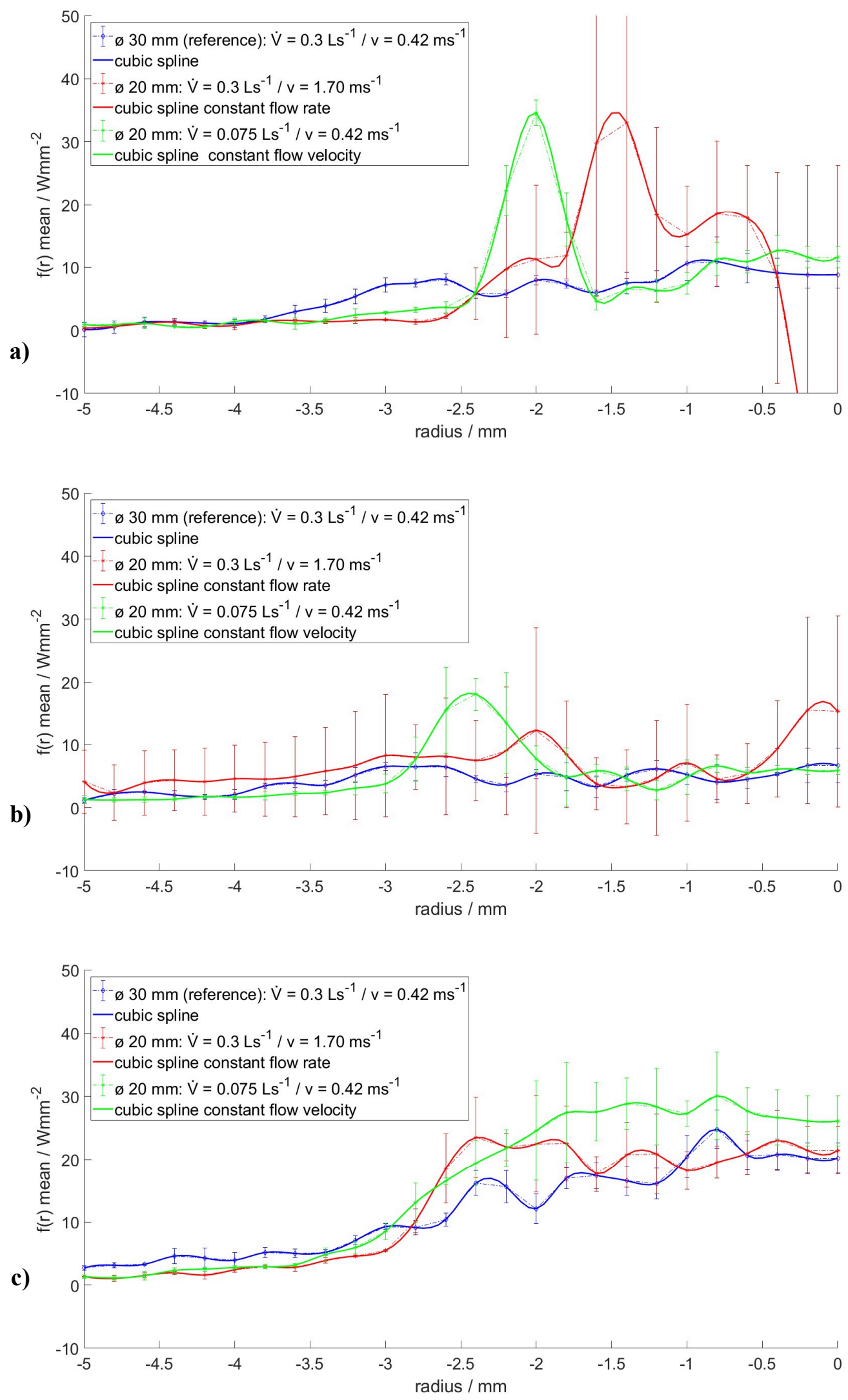


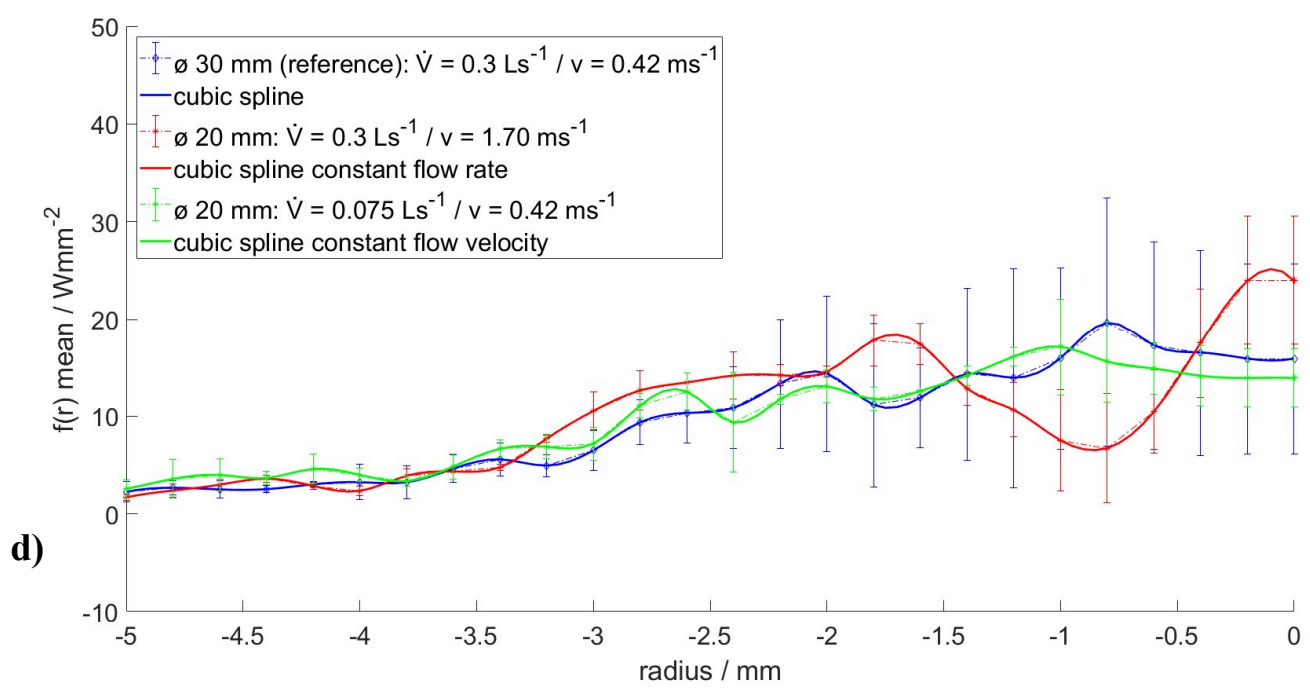

Figure 11 Calorimetric power density comparison of $50 \mathrm{~A}$ and $100 \mathrm{~A}$ welding current, using $20 \mathrm{~mm}$ diameter nozzle and maintaining either volumetric flow rate or flow velocity constant. Error bars represent standard deviation. $a-50 \mathrm{~A} / \mathrm{ETWD}=3.0 \mathrm{~mm} ; b-50 \mathrm{~A} / \mathrm{ETWD}=6.0 \mathrm{~mm} ; c-100 \mathrm{~A} /$ $\mathrm{ETWD}=3.0 \mathrm{~mm} ; d-100 \mathrm{~A} / \mathrm{ETWD}=6.0 \mathrm{~mm}$.

\subsection{Shielding chamber results - ETWD $3.0 \mathrm{~mm}$ and $6.0 \mathrm{~mm}$}

Figure 12 (a) compares the power density distribution deploying $3.0 \mathrm{~mm}$ ETWD along with $50 \mathrm{~A}$ welding current and both shielding chamber and the $30 \mathrm{~mm}$ reference gas nozzle used in our previous study [28]. Figure 12 (b) plots the heat input distribution when doubling the ETWD to $6.0 \mathrm{~mm}$. A density maximum away from the arc axis can be found for the lower ETWD $(3.0 \mathrm{~mm})$ fairly similar to the reference nozzle results. For the $6.0 \mathrm{~mm}$ arc gap this density maximum is less while overall there is a wider distribution of the arc power and an increase in noise towards the arc axis, which can be found with both reference nozzle and shielding chamber. It also can be seen that the noise in the measurement output increases for the larger ETWD and that no clear indication of a density maximum away from the arc axis occurs with the higher cathode distance.

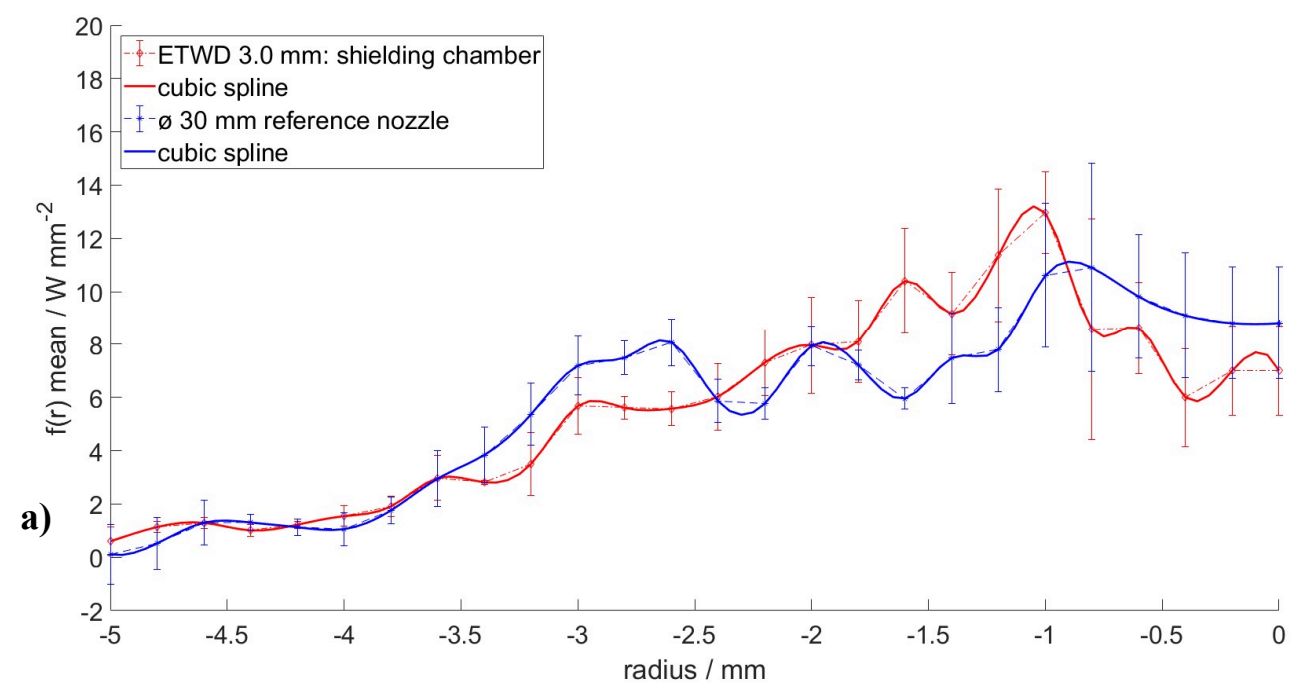




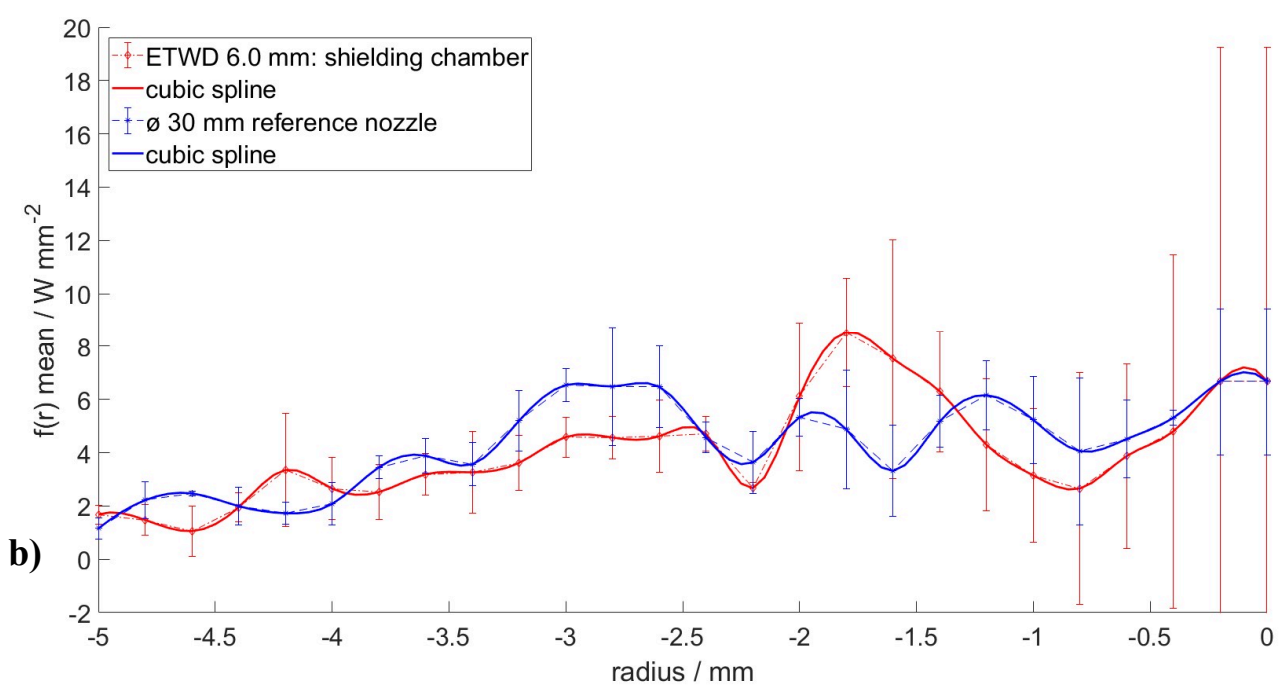

Figure $12 a$ Calorimetric power (red) and current density (blue) distribution applying the $30 \mathrm{~mm}$ diameter reference gas nozzle along with 50 A current and $3.0 \mathrm{~mm}$ ETWD; $b$ for 50 A current and 6.0 mm ETWD.

Figure 13 (a) depicts oxidation on the copper anodes after the experiment which is considerably less than that observed in the previous experiments Figure 13 (b) [28].

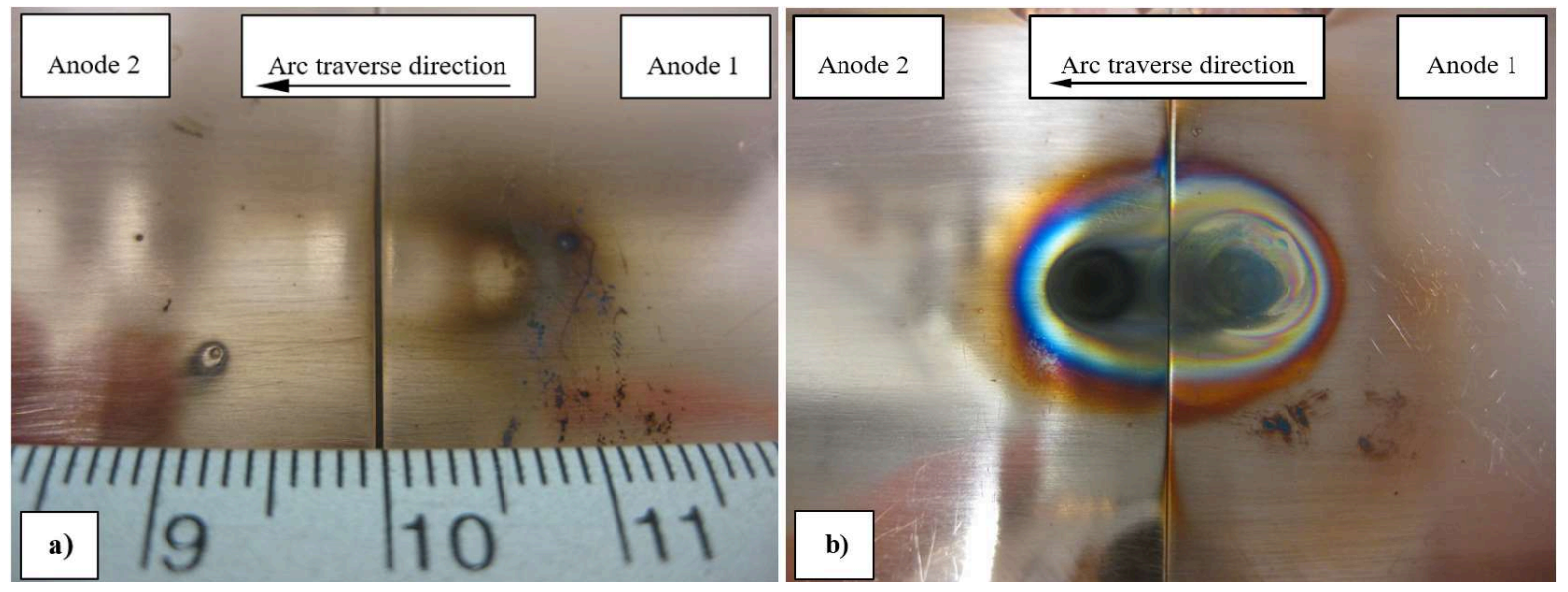

Figure $13 a$ Anode surface oxidation after arc application in shielding chamber; $b$ anode surface oxidation exemplarily as occurring in [28].

Unlike the application of the $15 \mathrm{~mm}$ and $20 \mathrm{~mm}$ diameter nozzle, and similar to our previous studies $[27,28]$, the shielded conditions led to high arc stability when traversing the arc across the split plane.

\subsection{Shielding gas flow}

Varying anode surface oxidation degrees could be observed throughout all measurement sequences, similar to the previous studies [27,28], although a double grid mesh diffuser, Figure 5 (b), was part of the prototype gas nozzles applied to produce laminar flow. Theoretical considerations, undertaken to identify the primary reasons for this surface oxidation [44], were also involving the case that the prototype gas nozzle may cause turbulent flow finally leading to the involvement of atmospheric gases thus surface oxidation.

Figure 14 (a) for the $5 \mathrm{~mm}$, and (b) for $10 \mathrm{~mm}$ shielding gas nozzle diameter shows for $3 \mathrm{~mm}$ ETWD turbulent flow conditions when applied to the base plate representing the split calorimeter anodes. Figure 14 (c) again for the $5 \mathrm{~mm}$ diameter nozzle and constant flow velocity of $0.42 \mathrm{~ms}^{-1}$; i.e. significantly reduced gas flow rates, reveals turbulent flow, which is initiated within the nozzle itself. Figure 14 (d) 
for the $10 \mathrm{~mm}$ diameter nozzle depicts a transition between laminar and turbulent flow behaviour while maintaining the flow velocity constant.
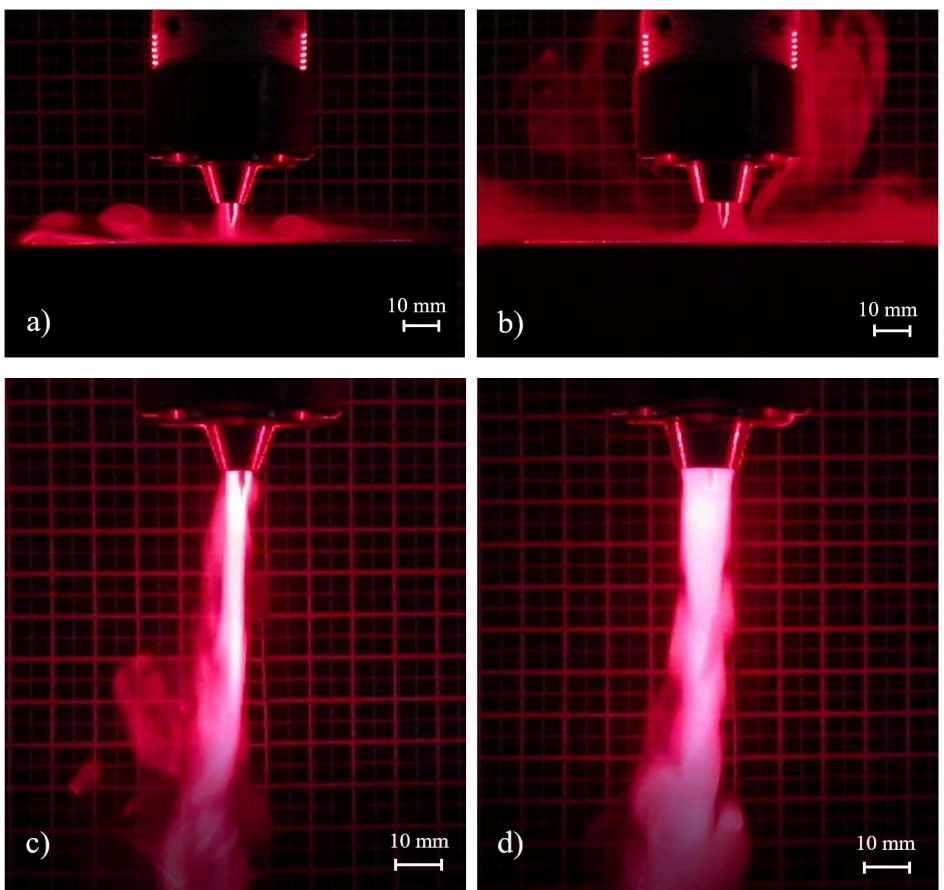

Figure $14 a$ turbulent flow pattern applying $0.3 \mathrm{Ls}^{-1}$ flow rate and $3 \mathrm{~mm}$ ETWD with $\varnothing 5 \mathrm{~mm}$ shielding gas nozzle; $b$ similar behaviour for $\varnothing 10 \mathrm{~mm}$ nozzle and maintaining ETWD and flow rate constant; $c$ turbulent flow with $5 \mathrm{~mm}$ diameter and constant flow velocity; however, applied in devoid of base plate; $d 10 \mathrm{~mm}$ diameter nozzle applied in devoid of base plate and maintaining flow velocity constant at 0.42 $\mathrm{ms}^{-1}$ producing transient flow behaviour.

Figure 15 (a) plots the flow pattern for $0.3 \mathrm{Ls}^{-1}$ volumetric flow rate, nozzle diameter of $15 \mathrm{~mm}$ and 3 mm ETWD; Figure 15 (b) for the same nozzle diameter visualises for the reduced flow rate, maintaining the flow velocity constant; while Figure 15 (c) and (d) depict the $20 \mathrm{~mm}$ diameter nozzle conditions.
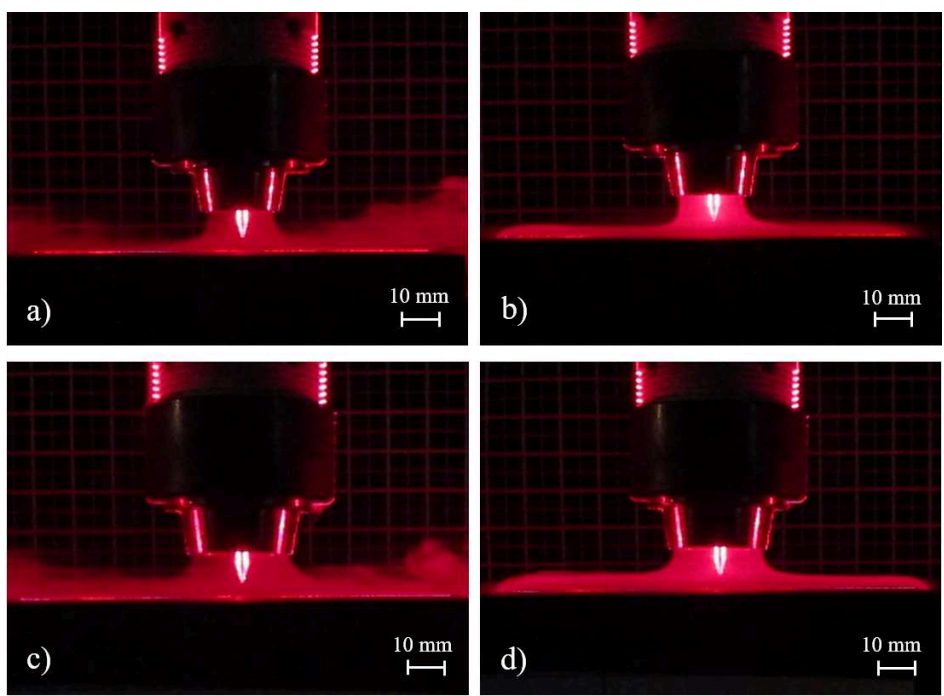

Figure $15 a$ Gas flow visualisation trials deploying $15 \mathrm{~mm}$ diameter shielding gas nozzle and maintaining $0.3 \mathrm{Ls}^{-1}$ gas flow rate constant; $b 15 \mathrm{~mm}$ nozzle maintaining flow velocity at $0.42 \mathrm{~ms}^{-1} ; c$ $20 \mathrm{~mm}$ diameter nozzle at $0.3 \mathrm{Ls}^{-1}$ gas flow rate; $d 20 \mathrm{~mm}$ nozzle at $0.42 \mathrm{~ms}^{-1}$ flow velocity. Note: $\mathrm{ETWD}=3.0 \mathrm{~mm}$ throughout.

For $6 \mathrm{~mm}$ ETWD Figure 16 (a) depicts the flow conditions in applying the $15 \mathrm{~mm}$ diameter shielding gas nozzle while maintaining the flow rate constantly at $0.3 \mathrm{Ls}^{-1}$. It becomes noticeable that the flow 
within the nozzle appears to be laminar whereas turbulences occur upon the anode surface surrounding the nozzle. Figure 16 (b), however, representing reduced flow rates to adjust the flow velocity constant to the reference value of $0.42 \mathrm{~ms}^{-1}$, shows smoothly uniform laminar flow both for nozzle and surface.
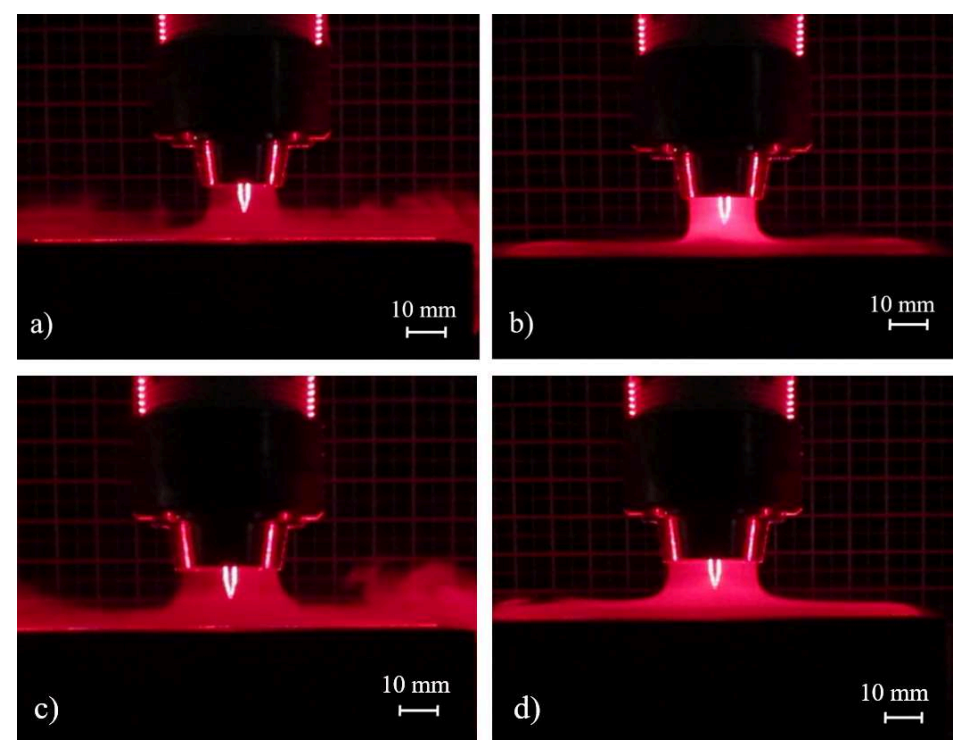

Figure $16 a$ Gas flow visualisation trials deploying $15 \mathrm{~mm}$ diameter shielding gas nozzle and maintaining $0.3 \mathrm{Ls}^{-1}$ gas flow rate constant; $b 15 \mathrm{~mm}$ nozzle maintaining flow velocity at $0.42 \mathrm{~ms}^{-1} ; c$ $20 \mathrm{~mm}$ diameter nozzle at $0.3 \mathrm{Ls}^{-1}$ gas flow rate; $d 20 \mathrm{~mm}$ nozzle at $0.42 \mathrm{~ms}^{-1}$ flow velocity. Note: $\mathrm{ETWD}=6.0 \mathrm{~mm}$ throughout.

Table 3 summarises the results, highlighting how laminar flow is obtained with the larger nozzle diameter. Turbulent flow was found throughout for the $5 \mathrm{~mm}$ nozzle type; except a laminar behaviour when deploying $0.3 \mathrm{Ls}^{-1}$ gas flow rate, and in part, when using the diameter $10 \mathrm{~mm}$ nozzle type and maintaining the flow velocity constant.

Table 3 Gas flow visualisation results for all prototype shielding gas nozzle types deployed. Note: 'transitional' describes a condition visually categorised since not clearly identifiable.

\begin{tabular}{ccc}
\hline $\begin{array}{c}\text { Nozzle diameter } \\
{[\mathbf{m m}]}\end{array}$ & $\begin{array}{c}\text { ETWD } \\
{[\mathbf{m m}]}\end{array}$ & $\begin{array}{c}\text { Flow condition } \\
{[---]}\end{array}$ \\
\hline 5 & 3 & turbulent \\
5 & 6 & turbulent \\
5 & $--{ }^{6}$ & turbulent/transitional \\
10 & 3 & turbulent/laminar \\
10 & 6 & turbulent/laminar \\
10 & ---7 & laminar \\
15 & 3 & laminar \\
15 & 6 & laminar \\
15 & ---7 & laminar \\
20 & 3 & laminar \\
20 & 6 & laminar \\
20 & ---7 & laminar \\
\hline
\end{tabular}

\subsubsection{Reynolds Number}

It was suggested amongst others in the previous study by the authors [28] that cathode jet variation may affect or cause surface oxidation, hence, detrimentally influencing measurement or calculated output. It is remaining unclear whether the copper oxide found is either produced while the arc is applied to the

\footnotetext{
${ }^{6}$ Application devoid of base plate.

${ }^{7}$ Gas flow velocity $0.42 \mathrm{~ms}^{-1}=$ const.
} 
anodes or after the arc interaction with the anode surface; virtually, as a high temperature reaction of the anode surface subsequent to the arc application.

Finding surface oxide layers also in applying the smaller shielding gas nozzle diameters, it appears consequently essential to understand the primary factors for surface oxidation; i.e. how can the anode oxidise although - theoretically - laminar shielding gas flow should have protected the arc interaction zone. Munson et al. [46] point out that categorising fluid flow precisely as "laminar, transitional, or turbulent" is not trivial because the final flow conditions are sensitively influenced by a number of different variables; it was nonetheless decided to take the Reynolds Number, expressing the ratio of the inertial over the viscous forces of a fluid, into greater account in this study. To assess and compare the experimental results dealt with in the foregoing sections, the dimensionless Reynolds Number $(R e)$ was calculated corresponding to each shielding gas nozzle diameter applied through the experimental series using expression (2):

$$
R e=\rho v_{0} D \mu^{-1}
$$

$\rho$ is the gas density and $v_{0}$ is the initial average gas velocity, considered here as equal to the gas flow velocity; $D$ is the nozzle diameter, and $\mu$ represents the gas viscosity.

For circular cross sections it is found that for $R e \lesssim 2.1 \times 10^{3}$ the flow is laminar-, while values between $\sim 2.1 \times 10^{3} \leq R e \lesssim 4 \times 10^{3}$ cause transitional-, and numbers of $\gtrsim 4 \times 10^{3}$ produce turbulent flow [46]. Johnson et al. [47], visualising shielding gas flow using particle image velocimetry (PIV), have attempted to factor the influence of nozzle design while applying commercial MIG/MAG shielding gas nozzles. To a rough approach we suggest that the nozzle design used in our study can be approximated similar to the geometry described in [47]. Table 4 depicts the essential data used for calculating the Reynolds Number.

Table 4 Essential argon and shielding gas nozzle data at ambient temperature.

\begin{tabular}{ccc}
\hline Parameter & Unit & Value \\
\hline Density $(\rho)^{8}$ & $\mathrm{kgm}^{-3}$ & 1.781 \\
Initial velocity $\left(v_{0}\right)$ & $\mathrm{ms}^{-1}$ & $1.7 / 0.95 / 0.42$ \\
Nozzle diameter $(\mathrm{D})$ & $\mathrm{m}$ & $0.015 / 0.020$ \\
Gas viscosity $(\mu)^{9}$ & $\mathrm{Kgm}^{-1} \mathrm{~s}^{-1}$ & 0.000021 \\
\hline
\end{tabular}

Table 5 shows that the Reynolds numbers calculated correlate well with the conditions found in the gas flow visualisation experiments previously dealt with.

Table 5 Reynolds number calculated for shielding gas nozzle diameters and gas flow conditions used. (Note, including ø $30 \mathrm{~mm}$ reference nozzle type).

\begin{tabular}{ccc}
\hline $\begin{array}{c}\text { Nozzle diameter } \\
{[\mathbf{m}]}\end{array}$ & $\begin{array}{c}\text { Flow velocity } \\
{\left[\mathbf{m s}^{-1}\right]}\end{array}$ & $\begin{array}{c}\text { Re } \\
(\mathbf{x ~ 1 0} \mathbf{~})\end{array}$ \\
\hline 0.005 & 15.3 & 6.488 \\
0.005 & 0.42 & -10 \\
0.010 & 3.8 & 3.223 \\
0.010 & 0.42 & -11 \\
0.015 & 1.7 & 2.163 \\
0.015 & 0.42 & 0.534 \\
0.020 & 0.95 & 1.611 \\
0.020 & 0.42 & 0.712 \\
$0.030^{11}$ & 0.42 & 1.069 \\
\hline
\end{tabular}

\footnotetext{
${ }^{8}$ 48. Brahinsky, H.S. and C.A. Neel, Tables of Equilibrium Thermodynamic Properties of Argon - Constant Pressure. 1969, Arnold Engineering Development Center Arnold AFB TN.

9 49. N.N. DiracDelta.co.uk - science and engineering encyclopedia. 2018 [cited 2018 24. June].

${ }^{10}$ After experimental failure using constant volumetric flow rate not further considered.

${ }^{11}$ Reference shielding gas nozzle diameter used in $28 . \quad$ Egerland, S., P. Colegrove, and S. Williams, Arc instabilities during split anode calorimetry with the TIG welding process. Welding in the World, 2018..
} 
The values in Table 5 explain that the $5 \mathrm{~mm}$ and the $10 \mathrm{~mm}$ diameter nozzle type resulted in turbulent shielding gas flow and severe arc instabilities, hence, were not considered further in this study.

\section{Discussion}

\section{Gas flow impact on arc stability and anode oxidation}

Although Table 5 shows laminar gas flow conditions actually to occur with the $15 \mathrm{~mm}$ and $20 \mathrm{~mm}$ shielding gas nozzle diameter, severe anode surface oxidation was found with these nozzle types, qualitatively increasing with the $15 \mathrm{~mm}$ diameter nozzle. According to Munson et al. [46] it appears difficult to assess clear values to distinguish fluid flow conditions. One of the reasons for the surface oxidation phenomena observed may be due to the fact that the aforementioned calculations are based on ambient temperature conditions and that the high temperature arc atmosphere may cause considerable deviations from these conditions. Turbulent flow may thus realistically occur while applying the smaller diameter nozzles even though laminar flow should theoretically prevail.

Comparing our findings with the results derived in [28], which measured the radial current density distribution, we could find a significant increase of noise in the measured calorimetric power density. The mechanisms, causing the instabilities may directly relate to the methodology deployed; i.e. split anode calorimetry, as long as not being applied under inert shielding gas conditions protecting the whole anode area, which we consider as a fundamental outcome of this study. We also suppose our suggestions described in [28] reasonably proved insofar as that the partially dramatic noise found was initiated by oxidation processes through arc plasma interaction with the copper anode surface, which prevented the stable process conditions, required to apply the mathematical approach used. From the results obtained we suppose further that the nozzle design or diameter respectively considerably impacts the measurement output. Slowly traversing low current arcs across the water-cooled anodes leads to contingent interaction with the surrounding atmosphere, amplified by small nozzle diameter and split plane interface, which resulted in different temperature conditions for the two anodes; hence, consequently causing deviations from arc symmetry through the measurement sequence, finally with drastic impact on the calculated results.

As anode oxidation is regularly not reported as a technical issue to overcome in industrial TIG welding applications, even with $15 \mathrm{~mm}$ or $20 \mathrm{~mm}$ nozzle diameters, the aforementioned study leads to an essential question. Is split anode calorimetry, as experimentally set up in our studies, capable of revealing data reflecting TIG welding arcs as industrially; i.e. practically applied? It is a question apparently remaining unsolved in this study; however, using the shielding chamber was helpful in that we could show that - under the given specific experimental boundary conditions - the radial energy density of low current TIG arcs is not necessarily Gaussian distributed and there are similar results between an arc that is well shielded locally and one that uses a chamber for protection.

Also, arc stability improved while increasing the weld current along with changing the radial energy density profile, to become more Gaussian distributed. This might imply that the studies conducted by other researchers $[29,31]$ that have applied high currents under inert ambient atmospheres have shown normal distributed energy density profiles both with respect to current and heat flux.

\section{Heat input density distribution}

The $15 \mathrm{~mm}$ diameter nozzle application showed for 50 A current and $3 \mathrm{~mm}$ ETWD a heat input density distribution that severely collapsed around the anode split plane with constant flow velocity, see Figure 10 (a), which was, however, not the case with adjusting a constant gas flow rate. Density maxima were found shifted away from the arc axis and more pronounced compared with the reference nozzle results. Hence, for the lower ETWD and $50 \mathrm{~A}$, a constant gas flow rate or increased flow velocity, leads to greater arc stability and density maxima away from the arc axis.

The behaviour stated by Tsai [32] and Tanaka and Ushio [11], who suggested that the arc length has essential effects on anode heat distribution, was confirmed in this study by doubling the electrode to work distance, which, however, was also connected to arc instabilities as already reported in our previous studies $[27,28]$. Hence, increasing the ETWD with the lowest applied current causes irregular 
output in the heat input calculations and the smaller nozzle diameter could not beneficially improve this behaviour. The wider heat density distribution radius found versus the current density in [28], is in agreement with the results derived by Schoeck [50], who, although applying different cathode diameters, described, that the "measurable heat transfer" is "only partly determined by the current". Also Tanaka et al. [35] reported that increased arc lengths reduce the heat input density by widening its distribution radius. Comparable to the current density [28] doubling the electrical current is leading to a more pronounced power increase towards the arc centre, as well as to less radial noise in the measurement, shown in Figure 10 (c). This confirms the findings of Tanaka and Ushio [10], Tsai [32], Tsai and Eagar [51], and Wu and Gao [19] who were reporting that "arc length" is primarily controlling the heat input to the anode; however the electron flux is in charge of controlling its magnitude.

Applying the $20 \mathrm{~mm}$ diameter nozzle led to heat input behaviour in the opposite direction versus the 15 $\mathrm{mm}$ diameter nozzle. In using the latter a density peak was derived by increasing the flow velocity, see Figure 10 (a), however, for the $20 \mathrm{~mm}$ nozzle, Figure 11 (a), a density maximum was found by increasing the flow rate. Since pronounced density maxima were not observed in deploying the $30 \mathrm{~mm}$ diameter reference nozzle type [28] we consequently suggest that the shielding gas nozzle diameter affects the radial heat input distribution, especially with regards to density maxima shifted away from the arc centre. It remains difficult to explain why both nozzle types are showing converse behaviour with respect to flow rate and flow velocity.

In addition to these results, it was most interesting that the shielding gas chamber trials conducted could lead to similar findings with respect to relatively clear off-axis density maxima, especially applying 3 $\mathrm{mm}$ ETWD, see Figure 12. Finding these peaks displaced $\sim 1.5 \mathrm{~mm}$ from the arc axis and rather less pronounced with the $6 \mathrm{~mm}$ ETWD trial series leaves us suggesting that low current arcs by applying the experimental conditions as in this study are not mandatorily Gaussian energy density distributed and smoothing the data with respect to the first derivative of $F(\mathrm{x})$ does not affect this distribution profile. Significantly reduced surface oxidation was found in the shielding chamber tests along with a considerably improved arc stability while traversing the arc across the split interface. This leads us to suggest that surface oxidation, produced while the arc is interacting with the anode surface, is decisively affecting the measured data and in turn has essential impact on the calculated radial energy density distribution. Comparing the present findings with our previous results on current density [28] we can find the heat input calculations more susceptible to noise which appears coherent, given the increased number of variables required to compute the calorimetric power input to the anodes. The wider distribution of arc power applying $6.0 \mathrm{~mm}$ ETWD also observed in the shielding chamber tests confirms the findings by Tanaka et al. [35] and Schoeck [50] as already previously discussed.

In general Gaussian-like heat input density distribution was not produced with our investigations with 50 A arcs; neither deploying a reference shielding gas nozzle, the smaller diameter nozzles, nor the shielding chamber. In conjunction to this non-Gaussian distribution, it is noteworthy that Heberlein and Pfender [52], who have used spectroscopy to determine "the radial distributions of electron temperature and electron density" of a 100 A non-consumable tungsten cathode arc, also found radial density maxima in between 1 and $2 \mathrm{~mm}$ from the arc axis. Besides this Heberlein and Pfender also report of facing experimental issues similar to our study; i.e. although "always an off-axis peak" was observed; its "radial location", as well as "the width of the distribution" was found varying "from run to run". Even though the primary reason for this shifted peak remained unsolved in [52] it may be correlated with the radial temperature distribution in the arc plasma when considering further the work by Vilarinho and Scotti [53]. These researchers have investigated TIG arcs of different currents and numerically simulated a temperature profile which shows $\sim 9000 \mathrm{~K}$ at approximately $2 \mathrm{~mm}$ away from the arc centre and applying a 40 A current arc. This temperature again can be correlated to the first ionisation stage [54] of argon, which in turn may lead to an increased electron-; i.e. current density, hence, representing an off-axis peak as also measured in our experiments.

Poloskov et al. [55] who numerically modelled the structure of 100 A TIG arcs, also found radial current and heat flow density off-axis peaks. While stating the current- and heat input density rather Gaussian distributed as long as numerically treating the arc as merely sustained upon a flat workpiece, the authors calculate explicit off-axis maxima at $\sim 1.5 \mathrm{~mm}$ and $2 \mathrm{~mm}$ radially displaced from the arc centre in case of assuming a "crater" in the weld pool. The distinction from normal distribution was further attributed to the "point of the smallest distance from the tip of the electrode to the surface of the welded 
component". It remains questionable whether this condition might be correlated to a split interface separating two anodes, thus explaining the off-axis peak found in our investigations.

\section{Conclusions}

From the experiments conducted and the theoretical considerations dealt with in this study, we can draw the following conclusions:

i. Given the experimental conditions applied, the shielding gas nozzle diameter does appear to have an influence on the anodic calorimetric power input.

ii. The instabilities found are caused by oxidation processes occurring through the arc application sequence and are more pronounced with the calorimetric power than with the current density distribution calculated in previous studies.

iii. Smaller shielding gas nozzles increase oxidation assumed due to poorer shielding and may cause turbulent shielding gas flow around the arc plasma.

iv. Protecting the whole anode area by using a shielding gas chamber led to highly stable TIG arc condition even with 50 A current and surface oxidation considerably less than with the smaller nozzle diameters.

v. The off-axis peak remains with the results from the shielding chamber, which leads us to suggest that lower current TIG arcs have non Gaussian-like energy density distributions and show off-axis maxima possibly adding or inducing arc-anode instabilities in practical welding applications; e.g. in welding light gauge butt joint configurations.

\section{Acknowledgements}

The authors are greatly indebted to FRONIUS International GmbH Wels, Austria, for the permit to use welding equipment and facilities, as well as for the provision of materials and consumables. Special gratitude is devoted to $\mathrm{Mr}$ Andreas Leonhartsberger for granting prompt and unselfish assistance in producing the shielding gas chamber and in conducting the shielding gas flow visualisation experiments.

\section{References}

1. Fihey, J. and R. Simoneau. Weld Penetration Variation in GTA Welding of some 304 L Stainless Steels. in Proc. Welding Technology for Energy Applications. May, 1982. Gatlinburg, TN.

2. Norrish, J., Advanced welding processes. 2006, Cambridge: Woodhead Publishing Ltd.

3. Schellhase, M., Der Schweißlichtbogen - ein technologisches Werkzeug. Fachbuchreihe Schweisstechnik. 1985, Düsseldorf (in German): Deutscher Verlag für Schweisstechnik. 236.

4. Lancaster, J.F., The Physics of welding. 1984, Oxford: Pergamon.

5. Vilarinho, L.O. and A. Scotti, Proposal for a modified Fowler-Milne Method to determine the Temperature Profile in TIG Welding at low Currents. Journal of the Brazilian Society of Mechanical Sciences and Engineering, 2004. 26(1): p. 34-39.

6. Weglowski, M., Determination of GTA and GMA Welding Arc Temperatures. Welding international, 2005. 19(3): p. 186-192.

7. Haddad, G. and A. Farmer, Temperature Determinations in a free-burning Arc. I. Experimental Techniques and Results in Argon. Journal of Physics D: Applied Physics, 1984. 17(6): p. 1189.

8. Farmer, A., G. Haddad, and L. Cram, Temperature determinations in a free-burning arc. III. Measurements with molten anodes. Journal of Physics D: Applied Physics, 1986. 19(9): p. 1723.

9. Degout, D. and A. Catherinot, Spectroscopic analysis of the plasma created by a double-flux tungsten inert gas (TIG) arc plasma torch. Journal of Physics D: Applied Physics, 1986. 19(5): p. 811.

10. Tanaka, M. and M. Ushio, Plasma State in free-burning Argon Arc and its Effect on Anode Heat Transfer. Journal of Physics D: Applied Physics, 1999. 32(10): p. 1153. 
11. Tanaka, M. and M. Ushio, Observations of the Anode Boundary Layer in free-burning Argon Arcs. Journal of Physics D: Applied Physics, 1999. 32(8): p. 906.

12. Terasaki, H., M. Tanaka, and M. Ushio, Effects of Metal Vapor on Electron Temperature in Helium Gas Tungsten Arcs. Metallurgical and Materials Transactions A, 2002. 33(4): p. 11831188 .

13. Lu, M. and S. Kou, Power and Current Distributions in Gas Tungsten Arcs. Weld. J.(Miami);(United States), 1988. 67(2): p. 29s-34s.

14. Tsai, M. and S. Kou, Heat Transfer and Fluid Flow in Welding Arcs produced by Sharpened and Flat Electrodes. International Journal of Heat and Mass Transfer, 1990. 33(10): p. 20892098.

15. Cram, L., L. Poladian, and G. Roumeliotis, Departures from equilibrium in a free-burning argon arc. Journal of Physics D: Applied Physics, 1988. 21(3): p. 418.

16. Wu, C., M. Ushio, and M. Tanaka, Analysis of the TIG Welding Arc Behavior. Computational Materials Science, 1997. 7(3): p. 308-314.

17. Biswas, K., A numerical prediction of the temperature distribution in the thermionic cathode of a welding arc. Journal of Materials Processing Technology, 1994. 40(1): p. 219-237.

18. Fan, H., H.-L. Tsai, and S. Na, Heat transfer and fluid flow in a partially or fully penetrated weld pool in gas tungsten arc welding. International Journal of Heat and Mass Transfer, 2001. 44(2): p. 417-428.

19. Wu, C. and J. Gao, Analysis of the Heat Flux Distribution at the Anode of a TIG Welding Arc. Computational Materials Science, 2002. 24(3): p. 323-327.

20. Ramírez, M.A., G. Trapaga, and J. McKelliget, A comparison between different numerical formulations for welding arc representations, J. Mater. Process. Tech. Journal of Materials Processing Technology, 2004. 155: p. 1634-1640.

21. Lu, F., et al., Modeling and Finite Element Analysis on GTAW Arc and Weld Pool. Computational Materials Science, 2004. 29(3): p. 371-378.

22. Lu, F., et al., Numerical Simulation on Interaction between TIG Welding Arc and Weld Pool. Computational Materials Science, 2006. 35(4): p. 458-465.

23. Hiraoka, K., A. Okada, and M. Inagaki, Effect of Electrode Geometry on Maximum Arc Pressure in Gas Tungsten Arc Welding. Quarterly Journal of the Japan Welding Society, 1985. 3(2): p. 246-252.

24. Kobayashi, K., et al., Practical Application of High Efficiency Twin-Arc TIG Welding Method (SEDAR-TIG) for PCLNG Storage Tank. Welding in the World, 2004. 48(7-8): p. 35-39.

25. Oh, D.S., Y.S. Kim, and S.M. Cho, Derivation of Current Density Distribution by Arc Pressure Measurement in GTA Welding. Science and Technology of Welding and Joining, 2005. 10(4): p. $442-446$.

26. Ham, H.S., D.S. Oh, and S.M. Cho, Measurement of arc pressure and shield gas pressure effect on surface of molten pool in TIG welding. Science and Technology of Welding and Joining, 2012. 17(7): p. 594-600.

27. Egerland, S., P. Colegrove, and S. Williams, Investigation of low current gas tungsten arc welding using split anode calorimetry. Science and Technology of Welding and Joining, 2016: p. $1-8$.

28. Egerland, S., P. Colegrove, and S. Williams, Arc instabilities during split anode calorimetry with the TIG welding process. Welding in the World, 2018.

29. Nestor, O.H., An Experimental Determination of Current Density and Heat Transfer Intensity Distributions at the Anode of High Current, Inert Gas Arcs, in School of Arts and Sciences. 1959, University of Buffalo: Buffalo, NY. p. 65-85. 
30. Nestor, O. and H. Olsen, Numerical Methods for reducing Line and Surface Probe Data. SIAM review, 1960. 2(3): p. 200-207.

31. Nestor, O.H., Heat Intensity and Current Density Distributions at the Anode of High Current, Inert Gas Arcs. Journal of Applied Physics, 1962. 33(5): p. 1638-1648.

32. Tsai, N., Heat Distribution and Weld Bead Geometry in Arc Welding, in Dept. of Materials Science and Engineering. 1983, Massachusetts Institute of Technology: Massachusetts, USA. p. 282.

33. Ushio, M., M. Tanaka, and J.J. Lowke, Anode Melting from free-burning Argon Arcs. Plasma Science, IEEE Transactions on, 2004. 32(1): p. 108-117.

34. Tanaka, M. and J.J. Lowke, Predictions of weld pool profiles using plasma physics. Journal of Physics D: Applied Physics, 2007. 40(1): p. R1-R23.

35. Tanaka, M., et al., Anode Heat Transfer in TIG Welding and its Effect on the Cross-Sectional Area of Weld Penetration. Welding International, 2006. 20(4): p. 268-274.

36. Füssel, U., et al., Experimentelle Möglichkeiten der WSG-Lichtbogenanalyse. Schweißen und Schneiden, 2007. 59(7): p. 396-403 (in German).

37. N.N., AWS Welding Handbook - Welding Processes-Part 1, ed. A. O'Brian. Vol. 2. 2004, Miami: American Welding Society.

38. Ramsey, G., et al., A computational fluid dynamic analysis of the effect of side draughts and nozzle diameter on shielding gas coverage during gas metal arc welding. Journal of Materials Processing Technology, 2012. 212(8): p. 1694-1699.

39. Campbell, S., et al., A computational fluid dynamic analysis of the effect of weld nozzle geometry changes on shielding gas coverage during gas metal arc welding. Journal of Manufacturing Science and Engineering, 2013. 135(5): p. 051016.

40. Dreher, M., et al., Numerical simulation of the shielding gas flow with GMA welding and options of validation by diagnostics. Mater. Sci. Technol, 2009. 2: p. 39-49.

41. Siewert, E., et al., Visualization of gas flows in welding arcs by the Schlieren measuring technique. Welding Journal, 2014. 93(1): p. 1-5.

42. N.N. Isobaric Properties for Water - Isobaric Data for $P=1.0000$ bar. 2018 17.11.2018]; Available from: https://tinyurl.com/yb89rrav.

43. N.N. Isobaric Properties for Water. 2018 17.11.2018]; Available from: https://tinyurl.com/yd4p2man

44. Norrish, J., Shielding gas nozzle design and gas flow conditions (Personal Discussion). 2018: Unpublished.

45. N.N. KASTILO Aramide Fibres. 2018 [cited 2018 13.10.]; Available from: http://www.kastilo.com/en/kastilo-technische-gewebe-gmbh-aramidfasern-kevlar-nomextwaron.

46. Munson, B.R., D.F. Young, and T.H. Okiishi, Fundamentals of Fluid Mechanics. 2nd ed. 1994, New York: John Wiley \& Sons, Inc. 893.

47. Johnson, D., P. Orakwe, and E. Weckman, Experimental examination of welding nozzle jet flow at cold flow conditions. Science and Technology of Welding and Joining, 2006. 11(6): p. 681687.

48. Brahinsky, H.S. and C.A. Neel, Tables of Equilibrium Thermodynamic Properties of Argon Constant Pressure. 1969, Arnold Engineering Development Center Arnold AFB TN.

49. N.N. DiracDelta.co.uk - science and engineering encyclopedia. 2018 [cited 2018 24. June]. 
50. Schoeck, P.A., An Investigation of the Anode Energy Balance of High Intensity Arcs in Argon', in 'Modern Developments in Heat Transfer. 1963, New York, USA: Academic Press New York. 353-400.

51. Tsai, N. and T. Eagar, Distribution of the Heat and Current Fluxes in Gas Tungsten Arcs. Metallurgical Transactions B, 1985. 16(4): p. 841-846.

52. Heberlein, J. and E. Pfender, Investigation of the Anode Boundary Layer of an Atmospheric Pressure Argon Arc. Plasma Science, IEEE Transactions on, 1977. 5(3): p. 171-180.

53. Vilarinho, L. and A. Scotti, Caracterização de arcos TIG via análise numérica. Soldagem \& Inspeção, 2006. 11: p. 200-207 (in Portuguese).

54. Marchandise, H., Plasmatechnologie - Grundlagen und Anwendung. DVS-Berichte Band 8. 1970, Düsseldorf (in German): Deutscher Verlag für Schweisstechnik.

55. Poloskov, S., V. Erofeev, and R. Logvin, Modelling the distribution of the heat flow and arc pressure in orbital TIG welding. Welding international, 2006. 20(1): p. 53-58. 


\section{Influence of shielding gas nozzle design on power density distribution in low-current TIG welding arcs}

\section{Egerland, Stephan}

Springer

Egerland S, Colegrove P, Williams S. (2020) Influence of shielding gas nozzle design on power density distribution in low-current TIG welding arcs. Welding in the World, Volume 64, May

2020, pp. 831-845

https://doi.org/10.1007/s40194-020-00876-5

Downloaded from Cranfield Library Services E-Repository 